\title{
Reconciled Estimates of Monthly \\ GDP in the US
}

Gary Koop, Stuart Mclntyre, James Mitchell and Aubrey Poon 
Reconciled Estimates of Monthly GDP in the US

Gary Koop, Stuart Mclntyre, James Mitchell and Aubrey

Poon ESCoE Discussion Paper No. 2020-16

November 2020

\begin{abstract}
In the US, income and expenditure side estimates of GDP (GDPI and GDPE) measure "true" GDP with error and are available at the quarterly frequency. Methods exist for producing reconciled quarterly estimates of GDP based on GDPI and GDPE. In this paper, we extend these methods to provide reconciled historical GDP estimates at the monthly frequency from 1960. We do this using a Bayesian Mixed Frequency Vector Autoregression involving GDPE, GDPI, unobserved true GDP and monthly indicators of short-term economic activity. We illustrate how the new monthly data contribute to our historical understanding of business cycles.
\end{abstract}

Keywords: Income; Output, Expenditure, Monthly, Business cycle, Expansion, Contraction, Recession, Turning point, State-space model, Vector autoregressions, Bayesian methods

JEL classification: EO1, E32

James Mitchell, University of Warwick, james.mitchell@wbs.ac.uk

Published by:

Economic Statistics Centre of Excellence

National Institute of Economic and Social Research

2 Dean Trench St

London SW1P 3HE

United Kingdom

www.escoe.ac.uk

ESCoE Discussion Papers describe research in progress by the author(s) and are published to elicit comments and to further debate. Any views expressed are solely those of the author(s) and so cannot be taken to represent those of the Economic Statistics Centre of Excellence (ESCoE), its partner institutions or the Office for National Statistics (ONS). 


\title{
Reconciled Estimates of Monthly GDP in the US
}

\author{
Gary Koop ${ }^{1,3}$, Stuart McIntyre ${ }^{1,3}$, James Mitchell ${ }^{* 2,3}$, and Aubrey Poon ${ }^{1,3}$ \\ ${ }^{1}$ University of Strathclyde \\ ${ }^{2}$ University of Warwick \\ ${ }^{3}$ Economic Statistics Centre of Excellence
}

November 2020

\begin{abstract}
In the US, income and expenditure side estimates of $G D P\left(G D P_{I}\right.$ and $\left.G D P_{E}\right)$ measure "true" $G D P$ with error and are available at the quarterly frequency. Methods exist for producing reconciled quarterly estimates of $G D P$ based on $G D P_{I}$ and $G D P_{E}$. In this paper, we extend these methods to provide reconciled historical GDP estimates at the monthly frequency from 1960. We do this using a Bayesian Mixed Frequency Vector Autoregression involving $G D P_{E}, G D P_{I}$, unobserved true GDP and monthly indicators of short-term economic activity. We illustrate how the new monthly data contribute to our historical understanding of business cycles.
\end{abstract}

Keywords: Income; Output; Expenditure; Monthly; Business cycle; Expansion; Contraction; Recession; Turning point; State-space model; Vector autoregressions; Bayesian methods

JEL Classification: EO1, E32

${ }^{*}$ Corresponding author: james.mitchell@wbs.ac.uk; Warwick Business School, The University of Warwick, Coventry, CV4 7AL, UK 


\section{Introduction}

Real Gross Domestic Product $(G D P)$ is the most widely used single but comprehensive measure of economic activity. In the US, the Bureau of Economic Analysis (BEA) provides quarterly estimates of real GDP based on Expenditures (E) and Income (I). This leads to two estimates of GDP: what we call $G D P_{E}$ and $G D P_{I} 1^{1}$ While theoretically equivalent, these two estimates can in practice differ substantially due to statistical discrepancies. This is because $G D P_{E}$ and $G D P_{I}$ are estimated using largely independent and imperfect source data; e.g. see Nalewaik (2010). The discrepancy between $G D P_{E}$ and $G D P_{I}$ can have important implications. As one example, while the quarterly annualized growth rate of real $G D P_{I}$ turned negative $3 \%$ in $2007 \mathrm{q} 3, G D P_{E}$ was still growing robustly (at an annualized rate of more than 2\%).2 This led to uncertainty about the timing of the 2007-2009 recession. As another example, consider Chang and Li (2018) who demonstrate that the common choice to use $G D P_{E}$ rather than $G D P_{I}$ in applied macroeconomic work can have a substantial effect on key empirical conclusions.

The desire for a reconciled or blended GDP estimate, that combines the information in both estimates, inspired Aruoba, Diebold, Nalewaik, Schorfheide and Song (2016), hereafter ADNSS, to develop an econometric modeling framework for producing historical estimates of "true" GDP. Their measurement-error framework views true $G D P$ as an unobserved, latent, variable with $G D P_{E}$ and $G D P_{I}$ being two noisy estimates of it ${ }^{3}$ Estimates of true $G D P$ are then obtained by applying optimal signal-extraction methods. The Federal Reserve Bank of Philadelphia use the ADNSS model in realtime to produce their popular reconciled quarterly measure of true real GDP growth: GDPplus.4

The present paper builds on ADNSS in several ways. First, ADNSS use quarterly data on $G D P_{E}$, $G D P_{I}$ and unemployment to produce quarterly estimates of true GDP growth. We develop mixed frequency models which exploit the fact that unemployment data (and many other macroeconomic indicators of short-term economic activity) are available at the monthly frequency to produce monthly real GDP growth estimates and measures of uncertainty associated with these estimates. Importantly, these monthly estimates of true $G D P$ are consistent with the published quarterly estimates of $G D P_{E}$ and $G D P_{I}$; but they exploit within-quarter information about economic activity gleaned from monthly

\footnotetext{
${ }^{1} G D P_{E}$ and $G D P_{I}$ are also often referred to as gross domestic product and gross domestic income (GDI), respectively. We do not use this particular nomenclature to emphasize that both $G D P_{E}$ and $G D P_{I}$ are estimates of the same underlying concept $(G D P)$ and in theory equal each other.

${ }^{2}$ This assessment is using latest (end of March 2020) vintage data, available at https://apps.bea.gov/histdata/ histChildLevels.cfm?HMI=7

${ }^{3}$ As ADNSS discuss, their model relates to and complements a wider literature on reconciliation of GDP measures dating back to Stone, Champernowne and Meade (1942).

${ }^{4}$ See https://www.philadelphiafed.org/research-and-data/real-time-center/gdpplus.
} 
indicators. An increasing range of monthly indicators, capturing specific aspects of overall economic activity, are widely consulted by economists who are interested in timely estimates of the state of the economy. Our methods provide a formal means of aggregating these monthly indicators to produce an estimate of the whole of GDP. While less satisfactory than direct measurement of monthly GDP by the BEA, as the recent Brave, Butters and Kelley (2019) index (henceforth BBK) and accompanying monthly $G D P_{E}$ (MGDP) estimates maintained by the Federal Reserve Bank of Chicago show $5^{5}$ policymakers find monthly estimates of real GDP growth useful. This view is supported by the NBER Business Cycle Dating Committee. On their home page (http://www .nber . org/cycles/recessions.html) they write: "The committee ...views real GDP as the single best measure of aggregate economic activity ... The traditional role of the committee is to maintain a monthly chronology of business cycle turning points. Because the BEA figures for real GDP [GDP $]$ and real GDI $\left[G D P_{I}\right]$ are only available quarterly, the committee considers a variety of monthly indicators to determine the months of peaks and troughs."

Second, Mixed Frequency Vector Autoregressions (MF-VARs) involving GDP growth (and many other macroeconomic variables) are enjoying increasing popularity for providing high frequency nowcasts or forecasts of low frequency variables (see, among many others, Eraker et al., 2015; Schorfheide and Song, 2015; Brave, Butters and Justiniano, 2019 and Koop et al., 2020). Most macroeconomic VARs include a variable reflecting real output growth. But conventionally this variable is based on one of the proxies for $G D P$, in fact almost always quarterly $G D P_{E}$. In this paper, we develop a MF-VAR where the output growth measure is (unobserved) true GDP. In other words, we embed the ADNSS structure within a MF-VAR. Given the growing interest in Big Data in general, and large VARs in particular, we show how our methods can be used with a large number of variables.

In order to develop our high-dimensional Bayesian MF-VAR we begin with a low dimensional VAR at the quarterly frequency similar to that used by ADNSS. This allows us to explain the general structure of the ADNSS model and, more importantly, discuss identification and prior elicitation issues. ADNSS consider various models and discuss several different identification schemes. One of these involves an instrumental variable assumption (specifically that the change in the unemployment rate correlates with true $G D P$ growth but is uncorrelated with the measurement errors in $G D P_{E}$ and $\left.G D P_{I}\right)$. The other involves restricting the variance of true GDP relative to the variance of $G D P_{E}$ to a specific number. We relax this assumption and, instead, show that bounding this ratio of variances to an interval leads to sensible estimates of true GDP. In other words, we relax the point

\footnotetext{
${ }^{5}$ See https://www.chicagofed.org/publications/bbki/index
} 
identification restriction of ADNSS to allow for set identification. This is a third contribution of this paper. It also sheds light on prior elicitation and allows us to develop a prior for the parameters controlling the relationship between $G D P, G D P_{E}$ and $G D P_{I}$ which we later use when we move on to the MF-VAR.

The plan of the remainder of our paper is as follows. Section 2 discusses the quarterly and monthly data. Section 3 introduces the structural VAR modeling framework used throughout. Section 4 then sets out and estimates various quarterly data reconciliation models. Having discussed identification and prior elicitation in these quarterly VARs, we move onto the MF-VAR in Section 5 . We explore various versions of this model, comparing their historical estimates of true monthly GDP growth and examining their time-series properties. We illustrate the utility of our new estimates of reconciled monthly $G D P$ by evaluating their ability to capture historical US business cycles; we showcase the usefulness of our methods in real-time in a case-study revisiting the 2007-9 recession; and we provide a brief update of our estimates in the light of the 2020 Coronavirus pandemic. Section 6 concludes. Online appendices include a full description of the data and our econometric methods as well as tables of supplementary empirical results.

\section{Quarterly and Monthly Data}

Our models all make use of quarterly real $G D P_{E}$ and $G D P_{I}$ data from the BEA. We supplement this, in some of our models, with monthly data on unemployment, hours worked, the consumer price index, the industrial production index, personal consumption expenditure (PCE), the Federal Funds rate, the Treasury bond yield and the S\&P 500 index. These 8 monthly variables are those considered by Schorfheide and Song (2015), although they add quarterly $G D P_{E}$, but not $G D P_{I}$, into their MF-VAR model. All provide monthly information on underlying economic activity. Indeed, some constitute the monthly source data used by the BEA to estimate quarterly $G D P_{E}$, or $G D P_{I}$; e.g. emphasizing its utility in measurement specifically of underlying monthly GDP, monthly PCE includes roughly $70 \%$ of real $G D P_{E}$. We also experiment, to demonstrate the utility of our methods with Big Data, with an even larger set of 50 monthly indicators (as summarized in the online Data Appendix) also believed to be helpful when tracking the evolution of the economy. This includes variables like monthly real personal income (which typically amounts to more than $80 \%$ of $\left.G D P_{I}\right)^{6}$

\footnotetext{
${ }^{6}$ Personal income equal national income minus corporate profits with inventory valuation and capital consumption adjustments, taxes on production and imports less subsidies, contributions for government social insurance, net interest and miscellaneous payments on assets, business current transfer payments (net), current surplus of government enterprises, and wage accruals less disbursements, plus personal income receipts on assets and personal current transfer
} 
that we should expect to closely track GDP. Later, to help establish the properties of our monthly $G D P$ estimates, we compare them to a range of monthly business cycle indicators and alternative estimates of monthly GDP.

Following the argument in ADNSS that measurement errors are best modeled as iid in growth rates rather than in levels, we work in a stationary model with the $G D P_{E}$ and $G D P_{I}$ data, and the other non-stationary macroeconomic indicators, modeled in growth rates. The online Data Appendix details data sources and the specific data transformations taken. Specifically, we use the log difference growth rate transformation 7 We emphasize that, following practice at the BEA and at the Chicago and Philadelphia Feds when publishing MGDP and GDPplus, respectively, we present monthly (and quarterly) GDP estimates as quarterly (quarter-over-quarter) annualized percent changes.

Following ADNSS, when presenting historical estimates of reconciled GDP, we focus on consideration of latest vintage $G D P_{E}$ and $G D P_{I}$ data. At the time of writing, these were (near end of) March 2020 vintage data; matching vintage data are used for the 8 and 50 indicator variables and for GDPplus. The historical sample period runs from 1960q1/1960m1 through 2019q4/2019m12. But, aware of the importance of data revisions, we do consider real-time data vintages in a case-study revisiting the 2007-9 recession. This lets us mimic real-time use of our models using the data available at the time. Specifically, we use 36 monthly vintages of $G D P_{E}$ and $G D P_{I}$ from the BEA over the period of this recession 8 , and combine these with monthly vintages of our monthly indicators taken from McCracken and Ng's (2016) FRED-MD database. We also briefly assess if/how our historical estimates are affected when we update our sample to include the Covid-19 pandemic period.

\section{Overview of the Econometrics}

All of the models used in this paper are either VARs or have a VAR as one of their main components. Accordingly, it is worth establishing some general notation which we use repeatedly in the remainder of the paper. We always work with VARs in structural form:

$$
A y_{t}=B y_{t-1}+\epsilon_{t}, \epsilon_{t} \sim N(0, \Sigma)
$$

receipts.

${ }^{7}$ We note that our model would work equally well using exact growth rates. But the temporal aggregation constraint introduced below would require modification as discussed, e.g., in Koop et al. (2020).

${ }^{8}$ Extracted from https://apps.bea.gov/histdata/histChildLevels.cfm?HMI=7 See Garciga and Knotek II (2019) for real-time data vintages for $G D P_{E}$ and $G D P_{I}$ extending further back in time (to 1992). 
for $t=1, \ldots, T$ where $y_{t}$ is a vector of $N$ dependent variables, $A$ is a lower triangular matrix with ones on the diagonal and $\Sigma$ is a diagonal matrix $9^{9}$ For future reference, denote the individual coefficients in $A$ and $B$ by $a_{i j}$ and $b_{i j}$. This form for the VAR is of particular use for computational reasons since the diagonality of $\Sigma$ allows for equation-by-equation estimation of the model. As stressed, e.g., in Carriero, Clark, and Marcellino (2019), this leads to large reductions in the computational burden which can be particularly useful in high-dimensional models. But the structural VAR form is also useful since some of the key data reconciliation relationships we use relate to the contemporaneous relationships between $G D P, G D P_{E}, G D P_{I}$ and unemployment and these all appear in $A$.

Bayesian estimation and forecasting for VARs involves choosing priors for $A, B$ and $\Sigma$ and then developing a Markov Chain Monte Carlo (MCMC) method for posterior and predictive simulation. We will discuss prior elicitation below in the context of the individual models. We provide only a brief description here of our MCMC methods since these are standard. Additional details are given in online Appendix A. In our models, some of the elements of $y_{t}$ are unobserved latent states (i.e. true GDP is such a state and in the MF-VAR the unobserved monthly values of $G D P_{E}$ and $G D P_{I}$ are states). In the context of Normal linear state space models such as we use in this paper, standard Bayesian MCMC methods exist for drawing the states. Accordingly, we do not describe these in any detail either. In sum, we use MCMC algorithms which provide draws of the VAR coefficients (conditional on the states) using standard methods and draws of the states (conditional on the parameters) using standard methods.

\section{Econometric Methods at the Quarterly Frequency}

We start at the quarterly frequency and, thus, in this section $t=1, \ldots, T$ in (1) denotes quarters.

\subsection{Models Involving Only GDP}

\subsubsection{Theory}

Many of the ADNSS results are obtained using the following model involving only the three GDP measures: expenditure side, $G D P_{E t}$; income side, $G D P_{I t}$ and true latent $G D P, G D P_{t}$. It is worth stressing that all these GDP measures enter in growth rates (e.g. $G D P_{E t}$ is the growth rate of $G D P_{E}$

\footnotetext{
${ }^{9}$ For simplicity, we write the VAR with one lag (a value we also use in our empirical work), no intercepts nor exogenous variables. Allowing for any or all of these is straightforward.
} 
constructed using the log-difference). ADNSS write their model in dynamic factor form as: 10

$$
\begin{aligned}
{\left[\begin{array}{c}
G D P_{E t} \\
G D P_{I t}
\end{array}\right] } & =\left[\begin{array}{l}
1 \\
1
\end{array}\right] G D P_{t}+\left[\begin{array}{c}
\epsilon_{E t} \\
\epsilon_{I t}
\end{array}\right] \\
G D P_{t} & =\rho G D P_{t-1}+\epsilon_{G t}
\end{aligned}
$$

where

$$
\left[\begin{array}{c}
\epsilon_{G t} \\
\epsilon_{E t} \\
\epsilon_{I t}
\end{array}\right] \sim i i d N\left[\left(\begin{array}{l}
0 \\
0 \\
0
\end{array}\right),\left(\begin{array}{ccc}
\sigma_{G G}^{2} & \sigma_{G E}^{2} & \sigma_{G I}^{2} \\
\sigma_{G E}^{2} & \sigma_{E E}^{2} & \sigma_{E I}^{2} \\
\sigma_{G I}^{2} & \sigma_{E I}^{2} & \sigma_{I I}^{2}
\end{array}\right)\right]
$$

Note that ADNSS adopt a measurement error perspective and (2) specifies a model for the measurement errors in expenditure and income side $G D P$ with true GDP itself following an $\operatorname{AR}(1)$ process.

It is straightforward to show that this model can be written as the VAR defined in (1) with $y_{t}=\left(G D P_{t}, G D P_{E t}, G D P_{I t}\right)^{\prime}$ and all the elements of $B$ zero except for $b_{11}$. The fact that the error covariance matrix in (4) is unrestricted implies that $A$ is unrestricted. This model is not identified.

ADNSS consider various ways of ensuring identification. First they show that identification is achieved if $\sigma_{G I}^{2}=\sigma_{G E}^{2}=0$. In words, the measurement errors in $G D P_{E t}$ and $G D P_{I t}$ are uncorrelated with $\epsilon_{G t}$. This restriction can be shown to imply a VAR as in (1) with $a_{21}=-1, a_{31}=-1+\sigma_{E I}$ and $a_{32}=-\sigma_{E I}$. Adopting the terminology of Mankiw and Shapiro (1986), we will refer to this restriction as the "noise" restriction - since this specification ensures that the volatility of true GDP is less than the volatility of $G D P_{E}$ or $G D P_{I}$. Thus, measurement error is purely noise, as opposed to the idiosyncratic variation in $G D P_{E}$ and $G D P_{I}$ containing "news" or information about the true state of the economy. If the measurement error is pure news, true $G D P$ is more volatile than either $G D P_{E}$ or $G D P_{I}$. As emphasized by Fixler and Nalewaik (2010), noise implies that more volatile GDP measures should be weighted less when reconciling alternative measures of true GDP; in contrast, news implies they should be weighted more heavily. Although there is some empirical evidence against the noise restriction (e.g. see Fixler and Nalewaik (2010) and Nalewaik (2010)), some variants of our models include this restriction; in others, we use it to center the prior (i.e. the prior mean satisfies the noise restriction).

Second, ADNSS introduce what they call a "useful re-parameterization" and introduce a new

\footnotetext{
${ }^{10}$ For expositional simplicity we are omitting intercepts, although ADNSS include one in the GDP equation, but not in the other equations.
} 
parameter they call $\xi$, which is the ratio of the variance of $G D P$ to the variance of $G D P_{E}$. They show that restricting $\xi$ to a specific value identifies the model. They present empirical results for a range of values of $\xi$. In a similar spirit, we introduce the parameters $\xi_{E}$ and $\xi_{I}$ which are the ratios of the variances of $G D P$ to $G D P_{E}$ and $G D P_{I}$, respectively. Posterior inference about these parameters can also be used to shed light on whether the measurement errors are purely noise or whether they contain news as well. That is, the noise restriction implies that $\xi_{E}$ and $\xi_{I}$ are both less than one. When working with a model which does not impose the noise restriction, we can calculate the posterior probability that either or both are greater than one.

We first emphasize that, although fixing $\xi_{E}$ or $\xi_{I}$ to a specific value suffices to identify the model, identification may not be necessary to ensure sensible inference about GDP. That is, identification is not necessarily required for the Bayesian. Combining an unidentified likelihood with a proper prior will yield a proper posterior. If a parameter is completely unidentified (i.e. does not appear in the likelihood function) and prior independence is assumed, then the posterior for the unidentified parameter equals its prior. However, in cases which are not completely unidentified and prior independence is not assumed, then posterior learning can occur even in unidentified models. Intuitively, posterior updating of the identified parameters can spill over onto unidentified parameters via the assumed prior links between them. See Poirier (1995) for a theoretical discussion of these points.

In our case, even if prior independence is assumed about the parameters in $(2),(3)$ and $(4), \xi_{E}$ and $\xi_{I}$ are nonlinear functions of parameters and it is possible that learning about them can occur even in this unidentified model. Furthermore, a prior which bounds $\xi_{E}$ and $\xi_{I}$ can be used to set-identify the model. In the following sub-section we demonstrate that set-identification can be used to estimate true $G D P$ and there is no need to fix $\xi_{E}$ and/or $\xi_{I}$ to specific values.

\subsubsection{Empirics}

We estimate the unrestricted quarterly VAR with latent $G D P$ in $(1)$, with $y_{t}=\left(G D P_{t}, G D P_{E t}, G D P_{I t}\right)^{\prime}$, using a prior that is similar in spirit to ADNSS's. That is, we begin with priors for error variances which are relatively non-informative inverse-Gamma priors and priors for VAR coefficients which are relatively non-informative Normal distributions. Priors on each parameter are independent of one another. Full details are given in online Appendix A.

ADNSS then restrict this prior such that $\xi_{E}$ is set to a specific value (e.g. $\xi_{E}=0.8$ ) so as to identify the model. This makes the actual prior used by ADNSS quite different from the apparently independent relatively non-informative prior they begin with. Instead of doing this, we achieve set 
identification by restricting $\xi_{E}$ and $\xi_{I}$ to lie within the interval $[0.55,1.15]$. This interval is fairly wide, expressing a range of different views about likely values for these two parameters accommodating both news and noise. ADNSS choose 0.8 as their benchmark and argue that $\xi_{E}$ is likely less than one (implying noise). Our choice of bounds reflects such beliefs. Posterior computation proceeds by using MCMC methods to draw from the unrestricted posterior (i.e. the posterior based on the VAR in 1 and the prior specified in the preceding paragraph) and discarding all draws which imply values of $\xi_{E}$ or $\xi_{I}$ outside the interval $[0.55,1.15]$. Following ADNSS, we include an intercept in the GDP equation, but not the equations for $G D P_{E}$ and $G D P_{I}$. This intercept is called $\mu$ in the table that follows.

Figures 1 and 2 plot the priors and posteriors, respectively for $\xi_{E}$ and $\xi_{I}$. It can be seen that the priors are sensible, allocating weight fairly evenly across the interval $[0.55,1.15]$, but with more weight allocated to values less than one. If we compare priors to posteriors the key point to note is that they are different. Despite the fact that this model is not identified, data-based learning about $\xi_{E}$ and $\xi_{I}$ occurs. It is also worth noting that the probability that $\xi_{E}$ is less than one is very close to one, indicating that the measurement error in $G D P_{E}$ is noise. For $G D P_{I}$, most of the posterior evidence also supports the noisy measurement errors conclusion, but it is not as strong indicating that there might be a news component to $G D P_{I}$. Fixler and Nalewaik (2010) found similar evidence, but based on modeling revisions to $G D P_{E}$ and $G D P_{I}{ }^{11}$ Almost five percent of the posterior probability for $\xi_{I}$ lies in the region above one, indicating some probability that measurement errors are news.

Table 1 presents posterior means and credible intervals for all the parameters in this model. All of the posterior means are reasonable (i.e. similar to those given in ADNSS) and the credible intervals are fairly narrow, indicating relatively precise inference despite the lack of identification. Finally, Figure 3 plots our quarterly estimates of true GDP (posterior medians) along with a $68 \%$ credible interval. The relatively narrow credible interval shows that true GDP is precisely estimated. Figure 3 compares these estimates of true GDP against the BEA's quarterly estimates of $G D P_{E}$ and $G D P_{I}$. It shows that our quarterly estimates of true $G D P$ do balance those of $G D P_{E}$ and $G D P_{I}$ and that they are smoother than both proxies; although it should be noted that the posterior median estimates of true $G D P$ do not always lie between the BEA's estimates of $G D P_{E}$ and $G D P_{I}$. They can be higher or lower than both. Over the sample period 1960q1-2019q4, the posterior median estimate of true

\footnotetext{
${ }^{11}$ As Fixler and Nalewaik (2010) show, exploiting revisions data (for $G D P_{E}$ and $G D P_{I}$ ) provides an alternative means of identification (to ADNSS) in models of data reconciliation that allow measurement errors to contain both news and noise components. Jacobs et al. (2018) develop this idea and propose a model to reconcile $G D P_{E}$ and $G D P_{E}$ data that exploits multiple data vintages. An extension of the monthly GDP models we develop below would also involve modeling data revisions.
} 
$G D P$ is more highly correlated with $G D P_{I}$ (correlation coefficient of 0.97 ) than $G D P_{E}$ (correlation coefficient of 0.91). This is consistent with the evidence in ADNSS that $G D P_{I}$ contributes more to true $G D P$ than $G D P_{E}$. It also fits with the fact that the posterior median estimates of true $G D P$, plotted in Figure 3, are very highly correlated (at 0.97) with ADNSS's estimates as measured by the published quarterly GDPplus series 12 This is as we should hope, given that the one aim of this paper was to embed ADNSS's quarterly measurement-error model within a Bayesian VAR model with set identification. In short, set identification suffices to produce reasonable estimates of true $G D P$ at the quarterly frequency, even in a model involving only the two proxies for GDP.

We have also produced results for this model with the noise restriction imposed (i.e. imposing $a_{21}=-1$ and $\left.a_{31}+a_{32}=-1\right)$. This restriction identifies the model and, thus, our prior is simply a prior rather than a means of imposing set identification. For the sake of brevity, we will not present empirical results for this case here. They are very similar to the set identified results. This is not surprising since the point estimates of $a_{21}, a_{31}$ and $a_{32}$ in Table 1 come close to satisfying the noise restriction.
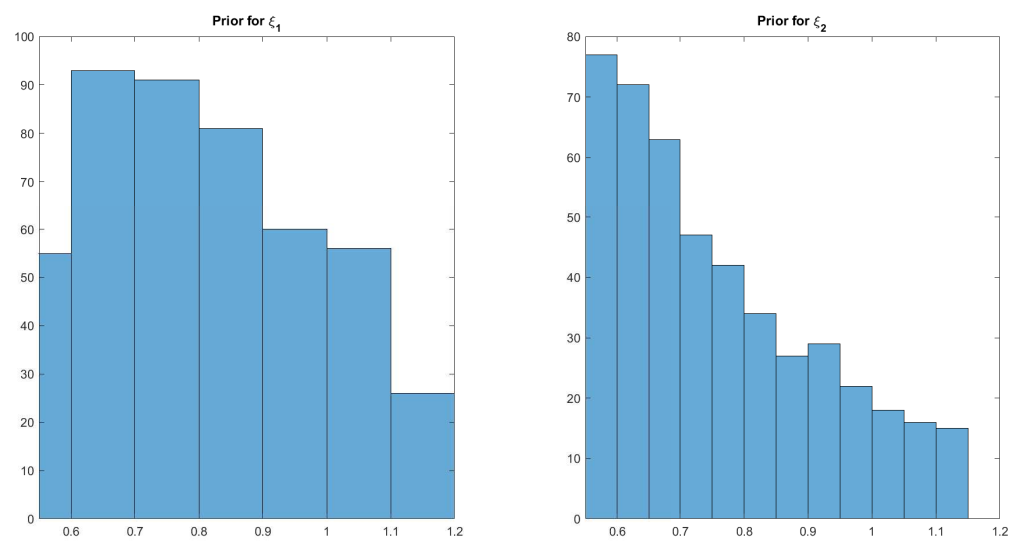

Figure 1: Prior distribution of $\xi_{E}$ and $\xi_{I}$

\subsection{An Identified Model Involving $G D P$ and Unemployment}

\subsubsection{Theory}

ADNSS also work with a model which is identified by adding the change in the unemployment rate, $U_{t}$, into the model. They provide a convincing argument that unemployment can be treated as

\footnotetext{
${ }^{12}$ Table 14 in online Appendix C provides these and other supplementary details on the time-series properties of our quarterly estimates of true $G D P$.
} 

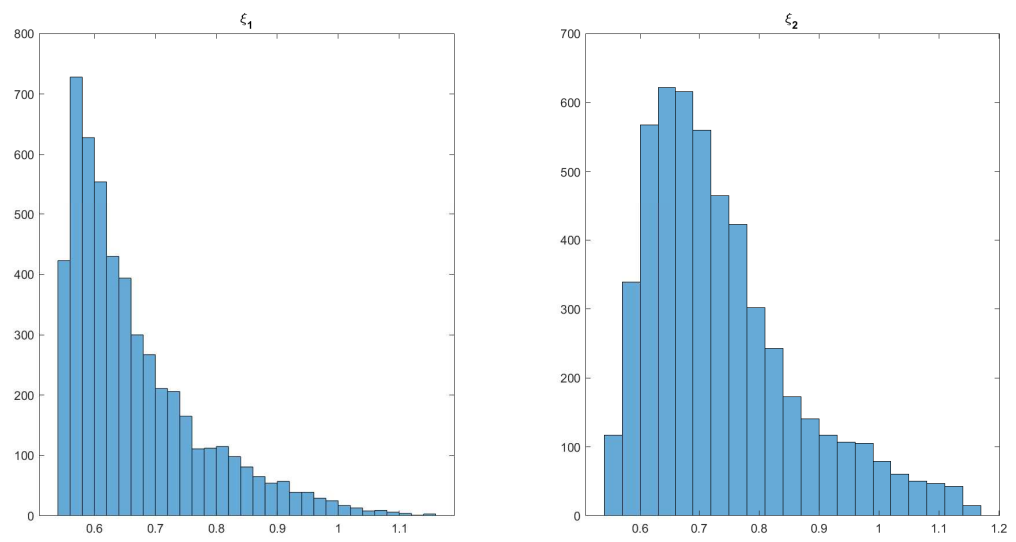

Figure 2: Posterior distribution of $\xi_{E}$ and $\xi_{I}$

an instrument for $G D P_{E}$ and $G D P_{I}$. Their argument is based on the fact that unemployment is constructed using household surveys (by the Bureau of Labor Statistics) whereas GDP measures are independently constructed (by the BEA) using business surveys and, thus, the measurement errors in the two estimates should be uncorrelated with one another.

Their model comprises (2), (3) and (4) with an additional equation for $U_{t}$ which says $U_{t}$ depends on $G D P_{t}$, but not on $G D P_{E}$ or $G D P_{I}$. It can be shown that this leads to a VAR representation based on (1) with the variables ordered as $y_{t}=\left(U_{t}, G D P_{t}, G D P_{E t}, G D P_{I t}\right)^{\prime}$ where

$$
\begin{aligned}
& A=\left[\begin{array}{cccc}
1 & 0 & 0 & 0 \\
a_{21} & 1 & 0 & 0 \\
0 & a_{32} & 1 & 0 \\
0 & a_{42} & a_{43} & 1
\end{array}\right] \\
& B=\left[\begin{array}{cccc}
b_{11} & b_{12} & 0 & 0 \\
b_{21} & b_{22} & 0 & 0 \\
0 & 0 & 0 & 0 \\
0 & 0 & 0 & 0
\end{array}\right]
\end{aligned}
$$

Note that this specification, in essence, breaks the model into two parts. One part is a bivariate VAR for unemployment and true GDP, the other is a structure inspired by ADNSS linking GDP to its two proxies. It captures the idea that $G D P$ belongs in the macroeconomic VAR and, once $G D P$ is included, $G D P_{E}$ and $G D P_{I}$ provide no additional explanatory power for any variable in the VAR other than GDP. The noise restriction now becomes $a_{32}=-1, a_{42}=-1+\sigma_{E I}$ and $a_{43}=-\sigma_{E I}$. 
Table 1: Point estimates and credible intervals for the parameters in the quarterly VAR model, (1), estimated in only $G D P_{E}$ and $G D P_{I}$

\begin{tabular}{cccc}
\hline \hline Parameters & Median & 16th quantile & 84th quantile \\
\hline$b_{11}$ & 0.56 & 0.48 & 0.65 \\
\hline$\mu$ & 1.32 & 1.06 & 1.59 \\
\hline$a_{21}$ & -0.96 & -1.08 & -0.83 \\
\hline$a_{31}$ & -0.72 & -1.03 & -0.49 \\
\hline$a_{32}$ & -0.27 & -0.44 & -0.04 \\
\hline$\sigma_{G G}^{2}$ & 5.30 & 4.64 & 6.51 \\
\hline$\sigma_{E E}^{2}$ & 3.21 & 2.32 & 4.25 \\
\hline$\sigma_{I I}^{2}$ & 1.96 & 1.44 & 2.42 \\
\hline$\xi_{E}$ & 0.63 & 0.57 & 0.77 \\
\hline$\xi_{I}$ & 0.71 & 0.62 & 0.86 \\
\hline \hline
\end{tabular}

Figure 3: Quarterly posterior median estimates of true US real GDP growth (blue lines) with $68 \%$ credible intervals versus $G D P_{E}$ (top panel) and $G D P_{I}$ (bottom panel) in black lines
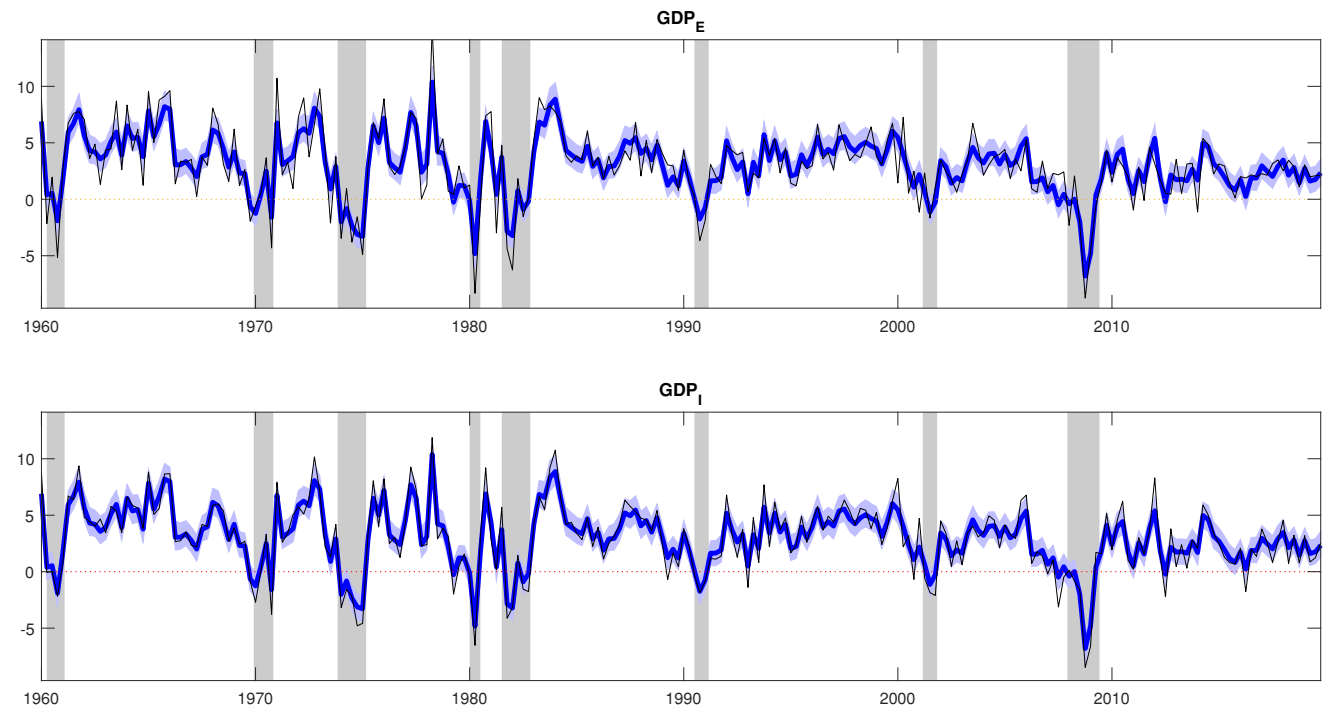

Notes: GDP growth in quarterly annualized percent changes from 1960q1-2019q4 (blue line) from the VAR model in only $G D P_{E}$ and $G D P_{I}$, as seen in Table 1 Shaded blue region is the interval between the 16th and 84th percentiles of the posterior density of true $G D P$. Black line shows the BEA's quarterly estimates of $G D P_{E}$ (top panel) and $G D P_{I}$ (bottom panel) growth. Vertical shaded areas represent NBER-defined recessions. 


\subsubsection{Empirics}

We have estimated three versions of the model with $A$ and $B$ restricted as in (5) and (6). The three versions impose the noise restriction, use a prior which is centered over this restriction and use a prior which is centered over zero, respectively. They give very similar results 13 We present results here using the version of the model with prior centered over the restriction. Following ADNSS, we put an intercept only in the equations for $U_{t}$ and $G D P_{t}$ and these are labeled $\mu_{1}$ and $\mu_{2}$ in the table below. The error variance in the equation for unemployment is labelled $\sigma_{U U}^{2}$.

Estimated results using this model are provided in Table 2. Again we find that the point estimates indicate that the noise restriction nearly holds. The posteriors of $\xi_{E}$ and $\xi_{I}$ allocate slightly more weight to larger values than in Table 1, but the point estimates are nearer the benchmark choice of ADNSS. As before, we find almost no evidence that $\xi_{E}>1$. However, for $\xi_{I}$ more than ten percent of the probability is above one. Thus the evidence for measurement errors being noise is strong, but not overwhelmingly so for $G D P_{I}$.

Another important comparison is between our quarterly estimates of true GDP and the GDPplus estimates produced by the Philadelphia Fed using this model. We plot both of these estimates in Figure 4. It can be seen that they match each other closely, as we should hope, with a correlation coefficient of 0.94 and with the GDPplus series falling within the $68 \%$ credible interval $89 \%$ of the time. ${ }^{14}$ Interestingly, the model presented in section 4.1, whose GDP estimates are plotted in Figure 3. was, as discussed above, even more closely correlated (correlation coefficient of 0.97) with GDPplus with GDPplus falling within its $68 \%$ credible intervals on $91 \%$ of occasions between 1960q1-2019q4. This all serves to reassure that our Bayesian approach to estimation of the ADNSS model, and our identification and prior elicitation strategy, is mimicking ADNSS's frequentist estimation approach under exact identification.

In summary, we have shown how to embed the data reconciliation models of ADNSS within a structural VAR framework where one of the variables (true $G D P$ ) is an unobserved latent variable. We have used this framework to show how true GDP can either be identified using an instrumental variables approach or using set identification, with little consequence for the time-series properties of

\footnotetext{
${ }^{13}$ We have also estimated an unrestricted version of the model which does not assume unemployment is an instrument and, thus, the model is only set identified using the bounded prior on $\xi_{E}$ and $\xi_{I}$. Results for this case were reasonable (i.e. as defined before, the estimates of GDP were broadly consistent with those in ADNSS), but credible intervals were wider. Accordingly, we use both the prior bounds on $\xi_{E}$ and $\xi_{I}$ and assume unemployment is an instrument in the remainder of this paper.

${ }^{14}$ Table 14 in online Appendix C provides these and other supplementary details on the time-series properties of our quarterly estimates of true GDP.
} 
true $G D P$. Finally, we have used insights from this exercise to discuss prior elicitation. In particular, we have demonstrated that it is useful either to impose the noise restriction or use a prior which is centered over this restriction. With this framework established, we now turn to the main goal of the paper: estimating monthly true $G D P$ using quarterly $G D P_{E}$ and $G D P_{I}$ and various monthly indicator variables.

Table 2: Point estimates and credible intervals for the parameters in the quarterly VAR model, (1), estimated in $G D P_{E}, G D P_{I}$ and including unemployment as an instrument

\begin{tabular}{cccc}
\hline \hline Parameters & Median & 16th quantile & 84th quantile \\
\hline$\mu_{1}$ & 2.26 & 1.91 & 2.67 \\
\hline$\mu_{2}$ & 0.39 & 0.28 & 0.50 \\
\hline$b_{11}$ & 0.46 & 0.40 & 0.53 \\
\hline$b_{12}$ & -0.14 & -0.17 & -0.10 \\
\hline$b_{21}$ & 0.48 & 0.27 & 0.70 \\
\hline$b_{22}$ & 0.22 & 0.12 & 0.32 \\
\hline$a_{21}$ & 0.22 & 0.12 & 0.32 \\
\hline$a_{32}$ & -1.00 & -1.11 & -0.90 \\
\hline$a_{42}$ & -1.01 & -1.21 & -0.81 \\
\hline$a_{43}$ & 0.00 & -0.17 & 0.17 \\
\hline$\sigma_{U U}^{2}$ & 0.91 & 0.83 & 1.00 \\
\hline$\sigma_{G G}^{2}$ & 7.00 & 5.52 & 9.04 \\
\hline$\sigma_{E E}^{2}$ & 2.24 & 1.72 & 2.90 \\
\hline$\sigma_{I I}^{2}$ & 1.47 & 1.09 & 1.92 \\
\hline$\xi_{E}$ & 0.75 & 0.61 & 0.94 \\
\hline$\xi_{I}$ & 0.81 & 0.66 & 1.01 \\
\hline \hline & & & \\
\hline \hline
\end{tabular}

\section{The MF-VAR with a Quarterly/Monthly Mixed Frequency}

In this section, $t=1, \ldots, T$ in (1) denotes time at the monthly frequency.

\subsection{Theory}

We return to the VAR model of Section 4.2, except that the model is now specified at the monthly frequency and we add additional monthly indicator variables to the VAR. Hence, $y_{t}=\left(X_{t}^{\prime}, U_{t}\right.$, 
Figure 4: Quarterly posterior median estimates of true US real GDP growth (blue line) versus the Philadelphia Fed's GDPplus (black line)

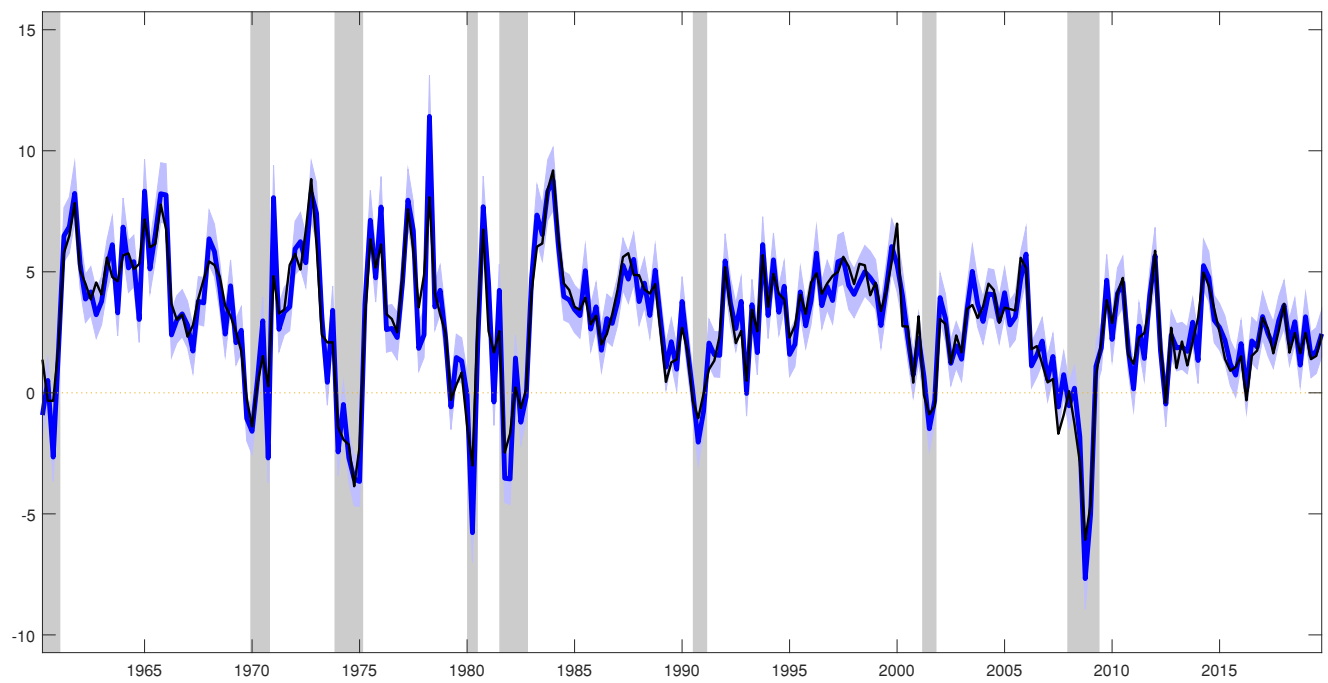

Notes: GDP growth in quarterly annualized percent changes from 1960q1-2019q4 (blue line) from the VAR model in $G D P_{E}, G D P_{I}$ and unemployment, as seen in Table 2 Blue shaded region is the 16th and 84th percentile interval of the posterior density of true $G D P$. Vertical shaded areas represent NBER-defined recessions

$\left.G D P_{t}, G D P_{E t}, G D P_{I t}\right)^{\prime}$ where $X_{t}$ is a vector containing other monthly indicator variables. $X_{t}$ and $U_{t}$ are observed, but the other elements of $y_{t}$ are not. True monthly $G D P$ is never observed. For $G D P_{E}$ and $G D P_{I}$ we observe quarterly values, but not monthly values. Thus, we have a MF-VAR. If it were not for the inclusion of true GDP, this would be a conventional MF-VAR as in, e.g., Schorfheide and Song (2015). The model we develop in this section combines the MF-VAR of Schorfheide and Song (2015) with the model of ADNSS so as to produce monthly estimates of true GDP. A side benefit is that we can also produce monthly estimates of $G D P_{E}$ and $G D P_{I}$ that are temporally consistent with the quarterly estimates published by the BEA.

The MF-VAR treats the VAR in (1) as state equations in a state space model. The measurement equations link what we observe (e.g. quarterly observations of $G D P_{E}$ and $G D P_{I}$ ) to the unobserved states (e.g. monthly values of $G D P_{E}$ and $G D P_{I}$ ) via an inter-temporal restriction. For the case of logdifferenced data, for a generic quarterly variable, $y_{t}^{Q}=\Delta_{3} \ln Y_{t}^{Q}$ where $Y_{t}^{Q}$ is the quarterly variable in levels (which we observe every third month), the link with its underlying monthly observations, 
$y_{t}^{M}=\Delta \ln Y_{t}$ where $Y_{t}$ is the monthly variable in levels, is approximately ${ }^{15}$

$$
y_{t}^{Q}=\frac{1}{3} y_{t}^{M}+\frac{2}{3} y_{t-1}^{M}+y_{t-2}^{M}+\frac{2}{3} y_{t-3}^{M}+\frac{1}{3} y_{t-4}^{M}
$$

Another ingredient in the measurement equations for $G D P_{E}$ and $G D P_{I}$ describes when they are observed. That is, quarterly variables are not observed in the first two months of the quarter, only for the third month (e.g. statistical agencies produce quarterly data for the quarter January, February, March, but not for February, March, April). Thus, the measurement equations for $G D P_{E}$ and $G D P_{I}$ are given by (7) in the third month of each quarter and do not exist in the first and second months. The equations are formally set out in online Appendix A.

For true $G D P$ there is no measurement equation since it is never observed either at the monthly or quarterly frequencies. For the monthly variables, the measurement equation simply reiterates that they are observed every month. These measurements, along with the monthly VAR of (1) define the likelihood function. It is a Normal linear state space model and, when combined with the priors used in this paper, standard Bayesian MCMC methods can be used for posterior and predictive simulation.

The MF-VAR just described is completely unrestricted (i.e. $A$ and $B$ have no restrictions placed on them) and is not identified. In practice, we impose the (zero) restrictions in (5) and (6) which involve the assumption that $U_{t}$ is an instrument. These are characterized by the features discussed at the end of Section 4.2.1 and the noise restriction remains the same as described there. We also face the issue of whether we want to place any restrictions on how the other monthly indicator variables enter the model. We consider two treatments of this issue. The first of these follows the common practice of treating $G D P$, unemployment and other monthly variables as defining a VAR independent of other sources of information. In other words, after controlling for $G D P$, the measurement errors in $G D P_{E}$ and $G D P_{I}$ do not have explanatory power for the other variables and do not belong in the VAR. This means all the monthly indicator variables are instruments in the same way as $U_{t}$, and the coefficients in the $A$ matrix corresponding to $X_{t}$ in the equations for $G D P_{E}$ and $G D P_{I}$ are set to zero. The second of these simply works with an unrestricted $A$ matrix, except for the restriction that implies $U_{t}$ is an instrument. The precise forms for the $A$ matrices that result are given in online Appendix A.

Finally, we consider some versions of our models which do not include $X_{t}$ to investigate whether including additional monthly indicators affects monthly estimation of true GDP. As discussed in

\footnotetext{
${ }^{15}$ See Mariano and Murasawa (2003, 2010) and Mitchell et al. (2005).
} 
Section 2, we consider both the 8 monthly variables considered in Schorfheide and Song (2015) and a larger set of 50 monthly indicators; these are denoted $X^{8}$ and $X^{50}$, respectively. SS is used in model acronyms to denote the MF-VAR of Schorfheide and Song (2015) with SS + denoting the SS model augmented with the larger set of 50 predictors.

Summarizing, in this section we propose models which involve four restrictions (the noise restriction, the restriction that unemployment alone is an instrument, the restriction that all the monthly variables are instruments and the restriction that additional monthly predictors are excluded from the MF-VAR). We always impose the restriction that unemployment is an instrument, even though we could relax this and rely on set identification instead. We do so, given the aforementioned evidence that imposing unemployment as an instrument sharpens our estimates of GDP. To assess the empirical relevance of the remaining restrictions, we produce empirical results from seven models which consider various combinations of them. Table 3 summarizes the features of these seven models.

As for the prior, we break the coefficients into two groups. The first of these are the parameters of the small quarterly VAR of sub-section 4.2. For these, we use the prior developed previously, which involves centering the prior over the noise restriction and bounding $\xi_{E}$ and $\xi_{I}$ to the interval $[0.55,1.15]$. The second are all the remaining parameters associated with the role of the potentially high dimensional vector $X_{t}$ in the VAR. For these we use a Dirichlet-Laplace prior. This is a popular global-local shrinkage prior which requires minimal prior hyperparameter choice and can automatically sort through the large number of VAR coefficients and decide which to shrink to zero. It has been used successfully with large VARs (see Kastner and Huber, 2020) and MF-VARs (see Koop et al., 2020). Full details are given in the online Appendix A. Bayesian inference and prediction can be carried out in the MF-VAR with the Dirichlet-Laplace prior using MCMC methods as described in Koop et al. (2020).

\subsection{Empirics}

\subsubsection{Model Comparison and Properties of Monthly GDP}

The main goal of the paper is to produce historical monthly estimates of true GDP growth. Given that the BEA does not produce estimates of monthly true $G D P$, against which we might evaluate our estimates, we compare the estimates produced by the seven models of Table 3 in various ways. We begin by taking the posterior median of historical monthly estimates of true $G D P, G D P_{E}$ and $G D P_{I}$ from each estimated model and calculate various summary descriptive statistics. These are 
Table 3: Summary of MF-VAR models used to estimate monthly GDP

\begin{tabular}{cccc}
\hline \hline Model & Monthly Variables & Noise imposed & Instruments \\
\hline $\mathrm{SS}(\mathrm{IV})$ & $X^{8}, U, G D P, G D P_{E}, G D P_{I}$ & $\mathrm{No}$ & $X^{8}, U$ \\
$\mathrm{SS}(\mathrm{IV}+\mathrm{N})$ & $X^{8}, U, G D P, G D P_{E}, G D P_{I}$ & Yes & $X^{8}, U$ \\
$\mathrm{SS}$ & $X^{8}, U, G D P, G D P_{E}, G D P_{I}$ & $\mathrm{No}$ & $U$ \\
$\mathrm{SS}(\mathrm{N})$ & $X^{8}, U, G D P, G D P_{E}, G D P_{I}$ & Yes & $U$ \\
$\mathrm{SS}+$ & $X^{50}, U, G D P, G D P_{E}, G D P_{I}$ & $\mathrm{No}$ & $U$ \\
$\mathrm{ADNSS}$ & $U, G D P, G D P_{E}, G D P_{I}$ & $\mathrm{No}$ & $U$ \\
$\mathrm{ADNSS}(\mathrm{N})$ & $U, G D P, G D P_{E}, G D P_{I}$ & Yes & $U$ \\
\hline \hline
\end{tabular}

given in Table 4. The overall impression is that the different models produce monthly GDP estimates which have very similar time-series properties. This broadly holds true for all three of our monthly $G D P$ estimates - true $G D P, G D P_{E}$ and $G D P_{I}$ - when comparing across models.

One interesting difference between models can be seen in the means and medians they produce. In models which impose the noise restriction, true $G D P$ must lie between $G D P_{E}$ and $G D P_{I}$. However, without the noise restriction, this does not necessarily occur. We also see that true GDP is always less volatile than both $G D P_{E}$ and $G D P_{I}$, except in the $\mathrm{SS}+$ model, which includes 50 monthly indicators. The SS model, with just 8 monthly indicators, also delivers true GDP estimates with volatility closer to $G D P_{E}$ and $G D P_{I}$ than the ADNSS model that considers unemployment only. In other words, consideration of additional monthly indicators does increase the relative volatility of the true GDP estimates. This is what we should expect, if these monthly indicators provide information about within-quarter economic dynamics.

In the $\mathrm{SS}+$ model with 50 additional monthly predictors, it can also be seen that true $G D P$, on average, is slightly higher than both $G D P_{E}$ and $G D P_{I}$. In the SS model, which is the same as $\mathrm{SS}+$ except that these additional monthly predictors are excluded, in contrast, true GDP on average lies between $G D P_{E}$ and $G D P_{I}$. Clearly, the additional monthly predictors are having an impact on our monthly $G D P$ estimates. Inspection of the posterior median estimates for $\sigma_{G G}^{2}$ also reveals the benefits of moving beyond consideration of monthly unemployment data alone: the ADNSS models offer poorer fit for the underlying monthly GDP equation than the SS models, with the exception of 
$\mathrm{SS}+$. This provides tentative evidence to suggest that, in-sample at least, consideration of 50 rather than just 8 additional monthly indicators may not provide informational value-added for underlying $G D P$. However, we re-emphasize the clear conclusion from Table 4 that inference about historical $G D P$ growth across the different models is very similar.

Comparing true $G D P$ with $G D P_{E}$ and $G D P_{I}$ we see from Table 4 that, across models, true $G D P$ is always more negatively skewed than either $G D P_{E}$ or $G D P_{I}$. The dynamics of monthly $G D P$ are also similar across models, with true $G D P$ and $G D P_{I}$ exhibiting slightly more persistence (as measured by the sample autocorrelations) than $G D P_{E}$. True $G D P$ and $G D P_{I}$ have smaller $\operatorname{AR}(1)$ innovation variance and greater predictability as measured by the $R^{2}$ than $G D P_{E}$.

The final column of Table 4 reveals that our monthly estimates of true GDP are more highly correlated with our estimates of monthly $G D P_{I}$ than monthly $G D P_{E}$. This is understood by inferring the relative contributions of $G D P_{I}$ and $G D P_{E}$ to true $G D P$. Following ADNSS, and also in the spirit of the least squares minimizations used in the data reconciliation literature (e.g. see Weale, 1985), we estimate the weight, $\lambda$, of $G D P_{I}$ in our monthly estimates of true $G D P$ :

$$
\lambda^{*}=\underset{\lambda}{\operatorname{argmin}} \sum_{t=1}^{T}\left[\left(\lambda G D P_{E, t}+(1-\lambda) G D P_{I, t}\right)-G D P_{t}\right]^{2}
$$

Table 5 confirms that $G D P_{I}$ is more important than $G D P_{E}$ in explaining true $G D P$, explaining up to two thirds of its variation. This new monthly result is consistent with the quarterly evidence in Fixler and Nalewaik (2010). Table 5 does indicate some modest differences across models in the combination weight, with the weight on $G D P_{E}$ rising when the noise restriction is imposed.

Posterior evidence relating to the noise restriction can also be found in the models which do not impose it. Table 6 shows, for $\xi_{E}$, there is virtually no probability that it is above one. Thus, the noise restriction is found to hold for $G D P_{E}$. However, for $\xi_{I}$ in the unrestricted model, there is an appreciable probability that it is greater than one. This evidence that the measurement error in monthly $G D P_{I}$ is at least in part news is consistent with the quarterly analysis in Fixler and Nalewaik (2010). Table 6 thus raises some doubts about whether it is sensible to impose the noise restriction. Thus our preference is for a model that allows for both news and noise.

Following Nalewaik (2010), we next calculate the correlations between our estimates of monthly true GDP growth and various other monthly business cycle indicators which should be correlated with true $G D P$ but that are measured independently. These indicators are the industrial production index (IPI), the change in the unemployment rate, the Institute for Supply Management's Purchasing 
Table 4: Descriptive statistics for the posterior median monthly GDP estimates, by model

\begin{tabular}{|c|c|c|c|c|c|c|c|c|c|c|c|c|c|}
\hline Model & Mean & Median & $\hat{\sigma}$ & Skew & $\hat{\rho_{1}}$ & $\hat{\rho_{2}}$ & $\hat{\rho_{3}}$ & $\hat{\rho_{4}}$ & $Q_{12}$ & $\hat{\sigma_{e}}$ & $R^{2}$ & $\widehat{\sigma}_{G G}^{2}$ & corr \\
\hline \multicolumn{14}{|c|}{ SS(IV) } \\
\hline$G D P_{t}$ & 2.86 & 2.91 & 2.87 & -0.39 & 0.92 & 0.74 & 0.53 & 0.39 & 1672.01 & 1.13 & 0.93 & 1.79 & 1.00 \\
\hline$G D P_{E, t}$ & 2.96 & 2.97 & 3.09 & -0.28 & 0.90 & 0.67 & 0.43 & 0.30 & 1309.52 & 1.36 & 0.90 & & 0.94 \\
\hline$G D P_{I, t}$ & 2.95 & 3.10 & 3.07 & -0.37 & 0.92 & 0.73 & 0.52 & 0.38 & 1656.15 & 1.21 & 0.92 & & 0.98 \\
\hline \multicolumn{14}{|c|}{$\mathbf{S S}(\mathbf{I V}+\mathbf{N})$} \\
\hline$G D P_{t}$ & 2.96 & 3.01 & 2.96 & -0.38 & 0.92 & 0.74 & 0.53 & 0.39 & 1651.82 & 1.17 & 0.93 & 1.90 & 1.00 \\
\hline$G D P_{E, t}$ & 2.96 & 2.97 & 3.09 & -0.28 & 0.90 & 0.67 & 0.44 & 0.30 & 1310.49 & 1.36 & 0.90 & & 0.95 \\
\hline$G D P_{I, t}$ & 2.95 & 3.11 & 3.07 & -0.37 & 0.92 & 0.73 & 0.52 & 0.38 & 1657.12 & 1.21 & 0.92 & & 0.97 \\
\hline \multicolumn{14}{|c|}{ SS } \\
\hline$G D P_{t}$ & 3.02 & 3.08 & 3.04 & -0.39 & 0.92 & 0.74 & 0.53 & 0.39 & 1673.83 & 1.19 & 0.93 & 2.00 & 1.00 \\
\hline$G D P_{E, t}$ & 2.96 & 2.97 & 3.09 & -0.28 & 0.90 & 0.67 & 0.44 & 0.30 & 1310.38 & 1.36 & 0.91 & & 0.94 \\
\hline$G D P_{I, t}$ & 2.95 & 3.11 & 3.07 & -0.37 & 0.92 & 0.73 & 0.52 & 0.38 & 1656.61 & 1.21 & 0.92 & & 0.98 \\
\hline \multicolumn{14}{|c|}{$\mathrm{SS}(\mathrm{N})$} \\
\hline$G D P_{t}$ & 2.96 & 3.01 & 2.96 & -0.39 & 0.92 & 0.74 & 0.53 & 0.39 & 1666.00 & 1.17 & 0.93 & 1.89 & 1.00 \\
\hline$G D P_{E, t}$ & 2.96 & 2.97 & 3.09 & -0.28 & 0.90 & 0.67 & 0.44 & 0.30 & 1309.86 & 1.36 & 0.90 & & 0.94 \\
\hline$G D P_{I, t}$ & 2.95 & 3.11 & 3.07 & -0.37 & 0.92 & 0.73 & 0.52 & 0.38 & 1656.80 & 1.21 & 0.92 & & 0.98 \\
\hline \multicolumn{14}{|c|}{ ADNSS } \\
\hline$G D P_{t}$ & 2.75 & 2.79 & 2.77 & -0.44 & 0.92 & 0.74 & 0.54 & 0.40 & 1681.63 & 1.08 & 0.93 & 2.23 & 1.00 \\
\hline$G D P_{E, t}$ & 2.97 & 2.98 & 3.09 & -0.32 & 0.90 & 0.67 & 0.44 & 0.30 & 1318.79 & 1.36 & 0.91 & & 0.93 \\
\hline$G D P_{I, t}$ & 2.95 & 3.09 & 3.08 & -0.41 & 0.92 & 0.73 & 0.52 & 0.38 & 1653.78 & 1.21 & 0.92 & & 0.98 \\
\hline \multicolumn{14}{|c|}{$\operatorname{ADNSS}(\mathbf{N})$} \\
\hline$G D P_{t}$ & 2.96 & 3.02 & 2.97 & -0.43 & 0.92 & 0.74 & 0.53 & 0.39 & 1654.73 & 1.17 & 0.93 & 2.63 & 1.00 \\
\hline$G D P_{E, t}$ & 2.97 & 2.97 & 3.10 & -0.32 & 0.90 & 0.67 & 0.44 & 0.30 & 1317.40 & 1.36 & 0.91 & & 0.95 \\
\hline$G D P_{I, t}$ & 2.95 & 3.09 & 3.08 & -0.41 & 0.92 & 0.73 & 0.52 & 0.38 & 1654.50 & 1.21 & 0.92 & & 0.97 \\
\hline \multicolumn{14}{|c|}{$\mathbf{S S}+$} \\
\hline$G D P_{t}$ & 3.08 & 3.21 & 3.11 & -0.40 & 0.92 & 0.74 & 0.53 & 0.39 & 1674.82 & 1.23 & 0.92 & 2.32 & 1.00 \\
\hline$G D P_{E, t}$ & 2.96 & 2.96 & 3.10 & -0.29 & 0.90 & 0.67 & 0.43 & 0.29 & 1300.50 & 1.37 & 0.90 & & 0.92 \\
\hline$G D P_{I, t}$ & 2.95 & 3.15 & 3.08 & -0.38 & 0.92 & 0.73 & 0.52 & 0.37 & 1643.02 & 1.23 & 0.92 & & 0.99 \\
\hline
\end{tabular}

Notes: The sample period is $1960 \mathrm{~m} 1-2019 \mathrm{~m} 12 . \quad \hat{\sigma}$ is the sample standard deviation. $\widehat{\rho}_{1}-\widehat{\rho}_{4}$ are the sample autocorrelations at displacements of 1 to 4 months. $Q_{12}$ is the Ljung-Box serial correlation test statistic calculated using $\widehat{\rho}_{1}, \ldots, \widehat{\rho}_{12} . R^{2}=\frac{\hat{\sigma}_{e}^{2}}{\hat{\sigma}^{2}}$, where $\hat{\sigma_{e}}$ is the estimated disturbance standard deviation from a fitted $\mathrm{AR}(1)$ model. $\widehat{\sigma}_{G G}^{2}$ are the posterior median estimates for $\sigma_{G G}^{2}$. corr is the correlation coefficient against $G D P_{t}$. 
Table 5: The proportionate contribution of $G D P_{E}$ in explaining $G D P: \lambda^{*}$ estimates by model

\begin{tabular}{cc}
\hline \hline & $\lambda^{*}$ \\
\hline $\mathbf{S S}(\mathbf{I V})$ & 0.37 \\
\hline $\mathbf{S S}(\mathbf{I V}+\mathbf{N})$ & 0.44 \\
\hline $\mathbf{S S}$ & 0.35 \\
\hline $\mathbf{S S}(\mathbf{N})$ & 0.40 \\
\hline $\mathbf{A D N S S}$ & 0.34 \\
\hline $\mathbf{A D N S S}(\mathbf{N})$ & 0.44 \\
\hline $\mathbf{S S}+$ & 0.27 \\
\hline \hline
\end{tabular}

Table 6: News versus noise by model: posterior probabilities that $\xi_{E}$ and $\xi_{I}$ are greater than one implying news

\begin{tabular}{cccc}
\hline \hline & $p\left(\xi_{E}>1\right)$ & $p\left(\xi_{I}>1\right)$ & $p\left(\xi_{E}>1\right.$ and $\left.\xi_{I}>1\right)$ \\
\hline $\mathbf{S S}(\mathbf{I V})$ & 0.00 & 0.01 & 0.00 \\
\hline $\mathbf{S S}(\mathbf{I V}+\mathbf{N})$ & 0.00 & 0.00 & 0.00 \\
\hline $\mathbf{S S}$ & 0.01 & 0.37 & 0.01 \\
\hline $\mathbf{S S}(\mathbf{N})$ & 0.00 & 0.00 & 0.00 \\
\hline $\mathbf{A D N S S}$ & 0.00 & 0.01 & 0.00 \\
\hline $\mathbf{A N D S S}(\mathbf{N})$ & 0.00 & 0.00 & 0.00 \\
\hline $\mathbf{S S}+$ & 0.00 & 0.51 & 0.00 \\
\hline \hline
\end{tabular}

Managers Index (PMI) for manufacturing, employment growth, the S\&P500 index and the Aruoba, Diebold and Scotti (ADS) business conditions index (aggregated to the monthly frequency from the underlying daily index data). Again, for those indicators that are revised, we use March 2020 vintage data; and all monthly indicators are converted to quarter-on-quarter annualized changes except the PMI which is analyzed in levels (as it is a balance statistic).

In addition, we consider the correlations against four alternative direct estimates of monthly $G D P$ computed by Stock and Watson (2014), IHS Markit, the OECD and BBK's estimates published at the Federal Reserve Bank of Chicago. All four monthly estimates are considered, like $y_{t}^{Q}$, as quarteron-quarter annualized log changes. Stock and Watson's (2014) GDP estimates, available monthly through 2010m6, are computed as the geometric average of their monthly estimates of $G D P_{E}$ and 
$G D P_{I}$. As real-time estimates are unavailable, we use the estimates accompanying their 2014 paper. IHS Markit, the global information provider, produce monthly GDP estimates from 1992m4 designed to be "an indicator of real aggregate output" and "whose variation at the quarterly frequency mimics that of official GDP" (see https://ihsmarkit.com/products/us-monthly-gdp-index.html), although we are unaware of the formal details of their methodology and any temporal aggregation constraints imposed. The OECD's monthly estimates of US real GDP are a leading indicator normalized to US GDP ${ }^{16}$ BBK use a collapsed dynamic panel model of over 500 monthly indicators and quarterly $G D P_{E}$ and, just like (7), ensure the monthly $G D P$ estimates temporally aggregate to the observed $G D P_{E}$ data ${ }^{17}$

From Table 7 it can be seen that the historical correlations with a given indicator are virtually identical across the seven models. This again points to the robustness of our historical estimates of monthly GDP. Reassuringly, we find an especially high correlation of our estimates of true GDP growth with the estimates produced by Stock and Watson (2014). While also highly correlated, we see a slight drop in the correlation of our estimates with the monthly GDP estimates produced by BBK. This is understood when we recall that BBK focus on consideration of $G D P_{E}$ and neither exploit $G D P_{I}$ data nor seek to provide reconciled $G D P$ estimates. Tables 15 and 16 in online Appendix $\mathrm{C}$ demonstrate that our models produce, reassuringly, monthly estimates of $G D P_{E}$ that are almost perfectly correlated with those of BBK; and our monthly estimates of $G D P_{I}$ are less strongly correlated (around 0.84) with BBK's estimates than our estimates of true GDP which, as shown in Table 7, are correlated at least 0.93 with BBK's estimates.

Table 13 in online Appendix $\mathrm{C}$ also shows that our monthly estimates, when aggregated to the quarterly frequency, correlate highly with the quarterly GDPplus estimates published by the Federal Reserve Bank of Philadelphia. Interestingly, our reconciled estimates of true GDP (when aggregated to the quarterly frequency to match GDPplus), while correlated around 0.93 are less correlated with GDPplus than our estimates of $G D P_{I}$. This suggests that consideration of monthly indicators about the state of the economy is in effect lowering the weight on $G D P_{I}$ in true GDP. Comparison of Table 5 with ADNSS's reported estimate that $\lambda=0.29$ on (quarterly) $G D P_{E}$ confirms the view that when measuring monthly $G D P$ a higher weight should be placed on $G D P_{E}$ and expenditure side components of economic activity.

Table 7 indicates that our estimates of true GDP growth are less strongly correlated with the

${ }^{16}$ The OECD's monthly indicator for US GDP is available from
https://fred.stlouisfed.org/series/USALORSGPNOSTSAM.
${ }^{17}$ See Box 2 of https://www.chicagofed.org/publications/economic-perspectives/2019/1


Table 7: Correlation by model of the posterior median of monthly $G D P_{t}$ growth with selected business cycle indicators and alternative estimates of monthly GDP growth (1960m1-2019m12)

\begin{tabular}{cccccc}
\hline \hline & OECD & S\&P500 & IPI & Unemployment & PMI \\
\hline $\mathbf{S S}(\mathbf{I V})$ & 0.84 & 0.27 & 0.81 & -0.68 & 0.68 \\
\hline $\mathbf{S S}(\mathbf{I V}+\mathbf{N})$ & 0.84 & 0.27 & 0.81 & -0.68 & 0.68 \\
\hline $\mathbf{S S}$ & 0.84 & 0.27 & 0.81 & -0.68 & 0.68 \\
\hline $\mathbf{S S}(\mathbf{N})$ & 0.84 & 0.27 & 0.81 & -0.68 & 0.68 \\
\hline $\mathbf{A D N S S}$ & 0.84 & 0.27 & 0.81 & -0.68 & 0.68 \\
\hline $\mathbf{A N D S S}(\mathbf{N})$ & 0.84 & 0.27 & 0.81 & -0.68 & 0.68 \\
\hline $\mathbf{S S}+$ & 0.84 & 0.27 & 0.81 & -0.68 & 0.68 \\
\hline \hline
\end{tabular}

\begin{tabular}{cccccc}
\hline \hline & Employment & Stock Watson & IHS Markit & ADS Index & BBK \\
\hline $\mathbf{S S}(\mathbf{I V})$ & 0.70 & 0.95 & 0.52 & 0.77 & 0.93 \\
\hline $\mathbf{S S}(\mathbf{I V}+\mathbf{N})$ & 0.70 & 0.96 & 0.52 & 0.77 & 0.95 \\
\hline $\mathbf{S S}$ & 0.70 & 0.96 & 0.52 & 0.77 & 0.93 \\
\hline $\mathbf{S S}(\mathbf{N})$ & 0.70 & 0.96 & 0.52 & 0.77 & 0.94 \\
\hline $\mathbf{A D N S S}$ & 0.70 & 0.95 & 0.53 & 0.78 & 0.92 \\
\hline $\mathbf{A D N S S}(\mathbf{N})$ & 0.71 & 0.96 & 0.53 & 0.77 & 0.95 \\
\hline $\mathbf{S S}+$ & 0.71 & 0.95 & 0.53 & 0.77 & 0.95 \\
\hline \hline
\end{tabular}

Notes: All monthly indicators except PMI are analyzed in quarterly (quarter-over-quarter) annualized percent changes. PMI is analyzed in levels. Due to data availability, the correlations reported for Stock-Watson and IHS Markit are over the shorter sample periods of 1960m1-2010m6 and 1992m4$2019 \mathrm{~m} 12$, respectively.

alternative estimates of monthly GDP produced by the OECD and IHS Markit, suggesting that these latter estimates are not designed to be consistent with quarterly GDP data. Turning to the correlations reported against the other macroeconomic indicators, we see that our monthly GDP estimates are highly positively correlated with industrial production and employment, and negatively correlated with unemployment. This is again reasonable and supports the plausibility of our estimates.

\subsubsection{Empirics: Further Perspectives on Monthly GDP}

Having established that historical inference about true GDP is fairly robust to which model we consider, here we present additional results from one of our models, the SS model, which imposes 
Figure 5: Monthly estimates (posterior medians) of $G D P$ (black line), $G D P_{E}$ (blue Line) and $G D P_{I}$ (red line) from the SS model

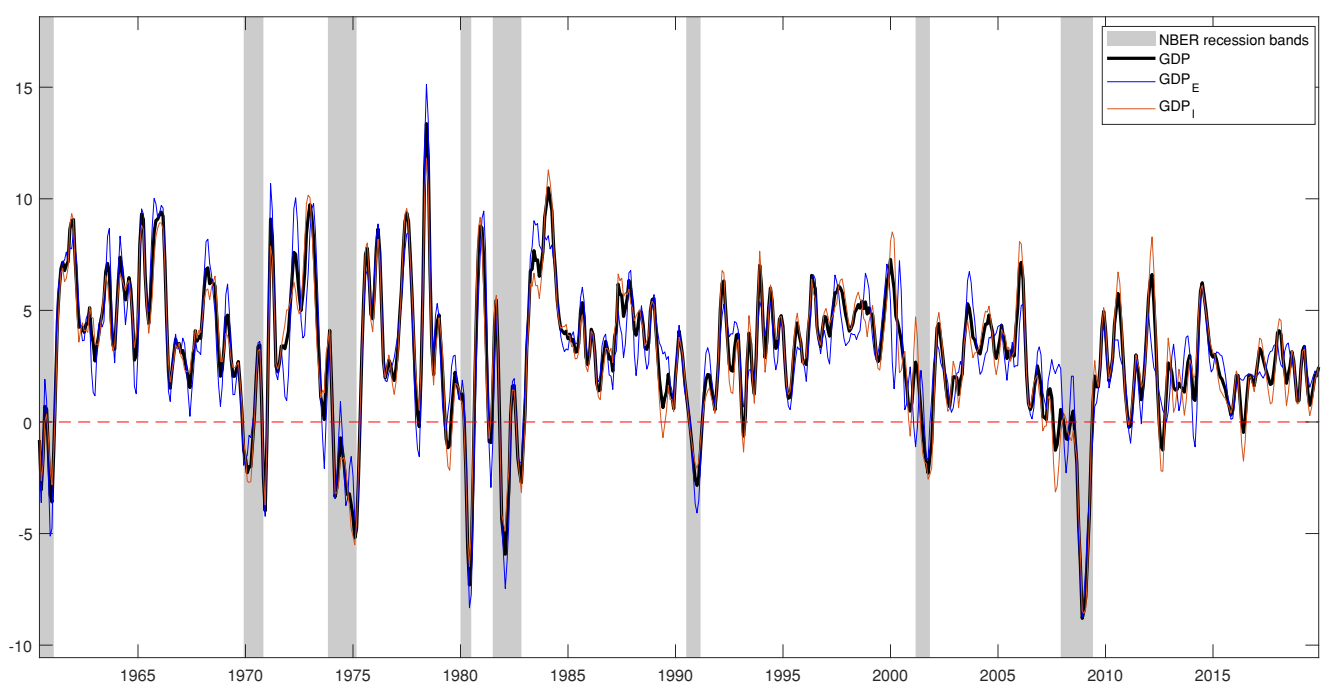

Notes: GDP growth in quarterly annualized percent changes from 1960m1-2019m12 (blue line) from the SS model. Vertical shaded areas represent NBER-defined recessions

neither the noise restriction nor the restriction that all the monthly variables are instruments (but does impose the restriction that unemployment is an instrument). We choose this as our preferred model given the empirical findings noted above. That is, the evidence in favor of the restrictions is not overwhelming. Since we are finding a high degree of robustness in that our seven models are producing similar estimates, we choose not to impose the restrictions. However, there is little evidence that moving from 8 to 50 monthly predictors improves our estimates and it does increase the computational burden substantially and, hence, we do not use the $\mathrm{SS}+$ model.

Figures 5 and 6 plot the monthly estimates of the three $G D P$ variables. It can be seen that the three lines tend to follow each other with true $G D P$ tending to lie between the estimates of $G D P_{E}$ and $G D P_{I}$, but there are some exceptions to this pattern. Note also that the credible intervals are quite narrow, indicating accurate estimation.

The SS model has a large number of parameters. For the sake of brevity, we do not present posterior information about all of them. We are particularly interested in the noise restriction and the restriction that all the monthly variables are instruments. Given the way we have ordered the variables in the MF-VAR, these restrictions relate to its tenth and eleventh equations. Thus, Table 8 presents results for these two rows in the $A$ matrix. The noise restriction implies $a_{10,9}=-1$ and 
Figure 6: Monthly estimates (posterior medians) of $G D P_{E}$ and $G D P_{I}$ growth (with $68 \%$ credible intervals) from the SS model versus BEA's quarterly estimates
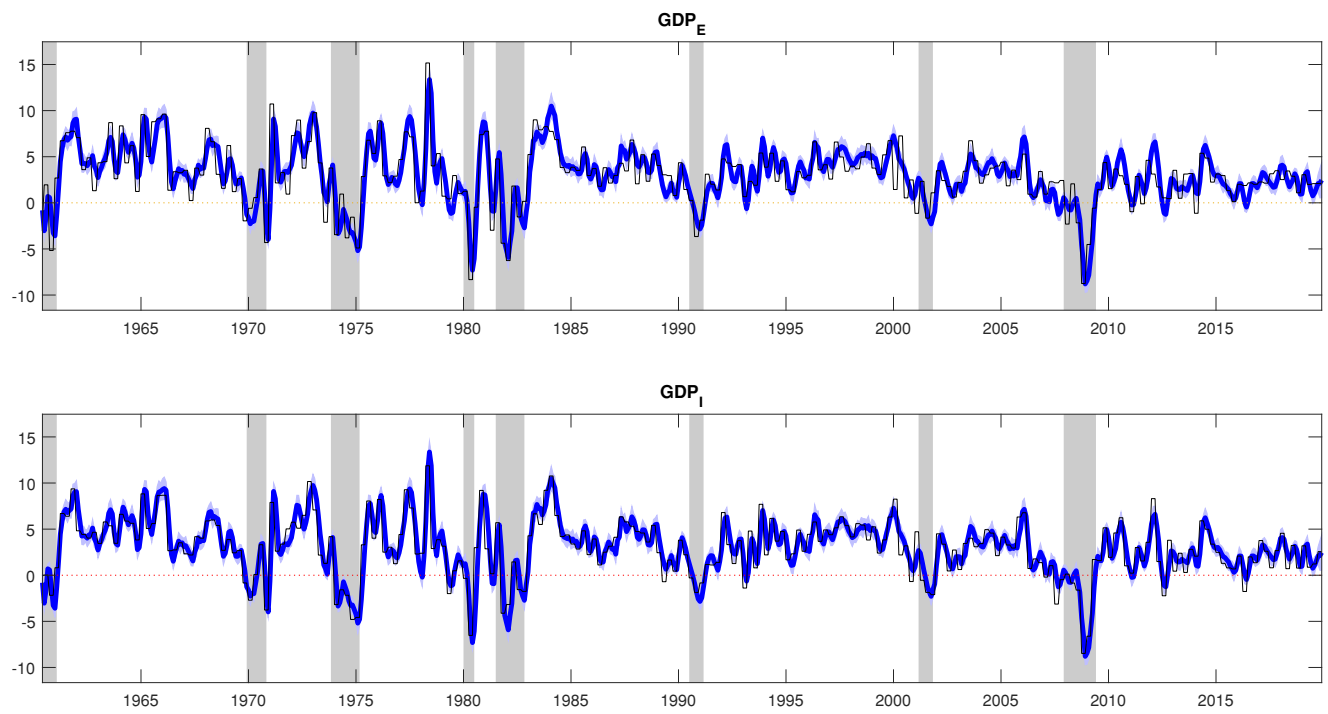

Notes: GDP growth in quarterly annualized percent changes from 1960m1-2019m12 (blue line) from the SS model. Black line shows the BEA's quarterly estimates of GDP growth (constant over a calendar quarter). Shaded areas represent NBER-defined recessions

$a_{11,9}=-1+a_{11,10}$. It can be seen that the point estimates are not too far from both restrictions. But, particularly for the noise restriction, the posterior allocates enough weight away from the restriction which accounts for the small differences between the restricted and unrestricted models noted in the preceding sub-section.

The posterior medians of all coefficients on the monthly variables in these two equations are zero to two decimal places, indicating that these variables are not strong instruments. Many of them have been shrunk to be extremely close to zero by the Dirichlet-Laplace prior. However, a small number of them have some posterior weight away from zero. Overall, these findings indicate that it is sensible to work with a monthly VAR involving true $G D P$ and the monthly indicators. Adding $G D P_{E}$ and $G D P_{I}$ to this VAR will not improve its explanatory power.

It is, of course, not possible to compare our estimates of true monthly GDP directly to monthly $G D P$ (or monthly $G D P_{E}$ or $G D P_{I}$ ), since none of these concepts are measured by the BEA. But it is informative to turn our monthly posterior density estimates for true GDP into quarterly posteriors, and then see how well they match with (the observed) quarterly $G D P_{E}$ and $G D P_{I}$ data from the 
Table 8: Posterior estimates of key parameters in $A$ from the SS model

\begin{tabular}{cccc}
\hline \hline Parameter & Median & 16th quantile & 84th quantile \\
\hline$a_{10,1}$ & 0.00 & -0.01 & 0.01 \\
\hline$a_{10,2}$ & 0.00 & -0.07 & 0.04 \\
\hline$a_{10,3}$ & 0.00 & -0.03 & 0.03 \\
\hline$a_{10,4}$ & 0.00 & -0.06 & 0.03 \\
\hline$a_{10,5}$ & 0.00 & -0.01 & 0.00 \\
\hline$a_{10,6}$ & 0.00 & 0.00 & 0.01 \\
\hline$a_{10,7}$ & 0.00 & -0.01 & 0.01 \\
\hline$a_{11,1}$ & 0.00 & 0.00 & 0.00 \\
\hline$a_{11,2}$ & 0.00 & -0.01 & 0.01 \\
\hline$a_{11,3}$ & 0.00 & 0.00 & 0.00 \\
\hline$a_{11,4}$ & 0.00 & 0.00 & 0.00 \\
\hline$a_{11,5}$ & 0.00 & 0.00 & 0.00 \\
\hline$a_{11,6}$ & 0.00 & 0.00 & 0.00 \\
\hline$a_{11,7}$ & 0.00 & 0.00 & 0.00 \\
\hline$a_{10,9}$ & -0.96 & -1.08 & -0.88 \\
\hline$a_{11,9}$ & -1.51 & -1.74 & -1.32 \\
\hline$a_{11,10}$ & 0.56 & 0.42 & 0.71 \\
\hline \hline
\end{tabular}


BEA ${ }^{18}$ This is achieved using the Probability Integral Transforms (PITs) histograms shown in Figure 7. These PITs are computed by integrating the posterior density for true GDP at time $t$ up to the realized value of $G D P_{E t}$ and $G D P_{I t}$. The PITs will be Uniformly distributed when the densities for true $G D P_{t}$ equal those of $G D P_{E t}$ or $G D P_{I t}$. It can be seen that for $G D P_{E}$, the PITs depart from Uniformity, placing extra weight in the tails. This sheds some light on the dispersion of the posteriors for true $G D P$ at each point in time. Because observed $G D P_{E}$ is often found to be in the tails of the posterior density of true $G D P$ this indicates its volatility is greater than for true GDP (as supported by Table 4 above). This is not true to the same extent for $G D P_{I}$. This is again as we should expect, given our findings relating to the noise restriction (seen in Table 6). That is, $G D P_{E}$ satisfies the noise restriction which implies it should be more volatile than true $G D P$. However, for $G D P_{I}$ there is less evidence in favor of the noise restriction. Hence the densities of true GDP and $G D P_{I}$ are more similar.

Figure 7: Probability Integral Transforms (PIT) histograms at the quarterly frequency for the true $G D P$ density from the SS model, using quarterly $G D P_{E}$ and $G D P_{I}$ data from the BEA as the realizations
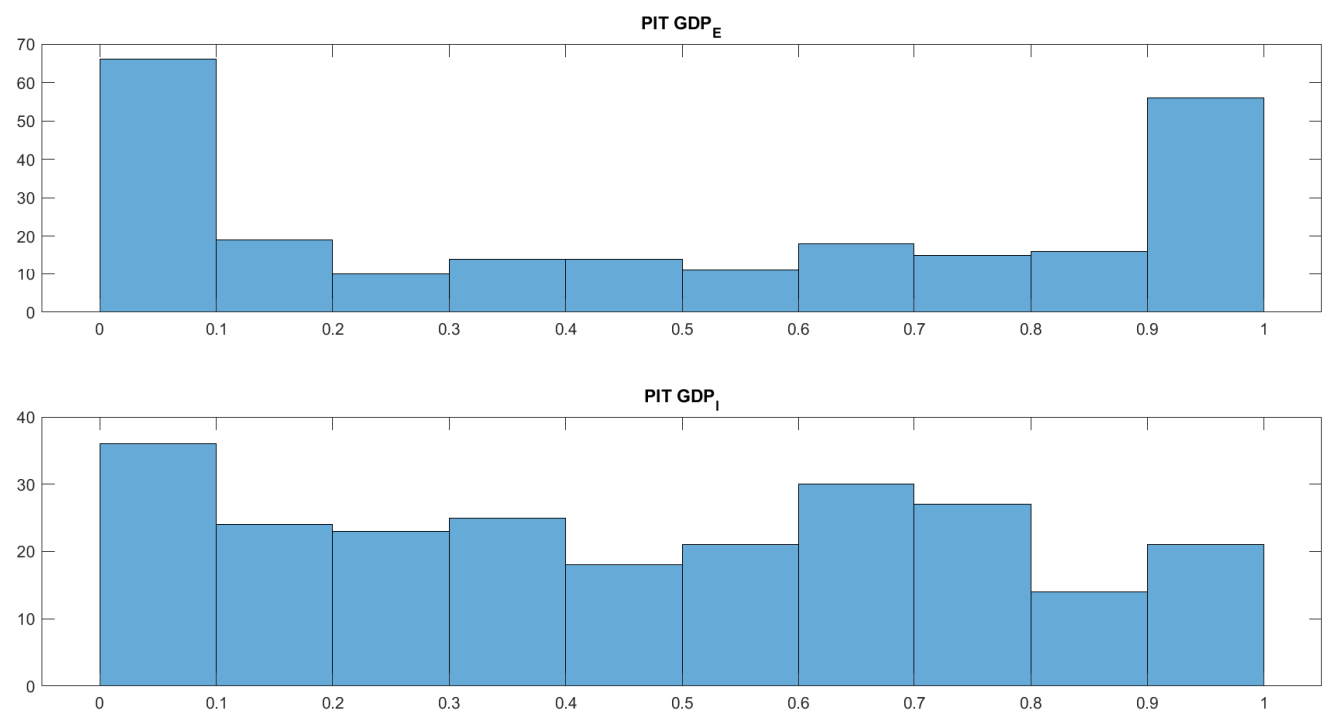

\subsubsection{Historical Business Cycles}

To illustrate the utility of our monthly estimates of true GDP, here we consider their ability to capture historical US business cycles as assessed by the NBER Business Cycle Dating Committee. An attraction of our Bayesian modeling approach, is that probabilities of recession can be readily

\footnotetext{
${ }^{18}$ Again we continue to use recent vintage data for this historical analysis.
} 
computed from our density estimates of monthly GDP. We proceed as follows. For each MCMC draw, we focus on monthly predictive estimates for $G D P$ growth, $y_{t}^{Q}$ (expressed as a quarterly change via (7)) and use these draws for $y_{t}^{Q}$ to date business cycle turning points. Specifically, we classify "recessions" and "expansions" non-parametrically like Berge and Jorda (2011) and Baker et al. (2019). This involves relating our historical estimates of monthly GDP, $y_{t}^{Q}$, from 1960m1 through 2019q4, to the NBER recession dates and finding the "optimal" threshold, $c$, such that a recession is declared for month $t$ when $y_{t}^{Q}<c$. We define the optimal threshold value as that $c$ that maximizes the area under the Receiver Operating Characteristic curve (AUC) giving equal weight to false positive and false negative signals $\sqrt{19}$ By performing this exercise across MCMC draws for $y_{t}^{Q}$, and computing the fraction of draws where $y_{t}^{Q}<c$, we produce full-sample recession probabilities acknowledging the uncertainty about $y_{t}^{Q}$. We do so using our monthly estimates for $G D P_{E t}$ and $G D P_{I t}$ as well as true $G D P_{t}$.

We plot these recession probabilities in Figure 8, continuing to focus (for expositional parsimony) on the SS model. Alongside, for comparison, we plot the recession probability estimates maintained by Jeremy Piger ${ }^{20}$ For consistency with our estimates, we use Piger's end of March 2020 vintage estimates that date back to $1967 \mathrm{~m} 6$. Rather than using a non-parametric dating algorithm to define recessions and expansions, Piger's probability estimates are calculated from a dynamic factor Markovswitching model developed by Chauvet (1998) applied to four monthly variables. Chauvet and Piger (2008) analyze the performance of this model for dating recessions.

Figure 8 shows that the recession signals from the monthly SS model align well with NBER recessions. While the probabilities of recession do rise to one during NBER recessions, what is relevant for our purposes is that the strength of the signal varies depending on whether one consults true $G D P, G D P_{I}$ or $G D P_{E}$. The recessionary probabilities based on true $G D P, G D P_{I}$ and $G D P_{E}$ often differ, with false signals most evident when one consults $G D P_{I}$ or $G D P_{E}$ alone. This impression is confirmed when in Table 9 we follow Berge and Jorda (2011) and Baker et al. (2019) and formally evaluate the classification ability of the different recession probability estimates seen in Figure 8 by reporting their AUC values.

Table 9 shows that dating NBER recessions using true GDP delivers $94 \%$ accuracy. Only $6 \%$ of estimates of true monthly GDP are ambiguous i.e. consistent with both a recessionary and expansionary classification. But accuracy drops to $92 \%$ when using $G D P_{I}$ or $G D P_{E}$ alone: reconciling the

\footnotetext{
${ }^{19}$ This corresponds to choosing $c$ to maximize the Youden Index.

${ }^{20}$ See https://pages.uoregon.edu/jpiger/us_recession_probs.htm/
} 
information in these two proxies of GDP provides better classification ability. These improvements for true GDP in dating recessions and expansions are statistically significant at the $2 \%$ and $8 \%$ levels against $G D P_{I}$ and $G D P_{E}$, respectively ${ }^{21}$ BBK's monthly $G D P$ estimates perform similarly to $G D P_{I}$ and $G D P_{E}$, with again true $G D P$ providing superior classification performance. A comparison in Table 9 against broader measures of economic activity as captured by BBK's Index and the ADS index does show, as anticipated, that when focused exclusively on dating the NBER business cycle, information beyond monthly GDP helps. ${ }^{22}$ Piger's set of recession probabilities, calibrated specifically to signal NBER recessions, provide near perfect classification.

Our conclusion from Table 9 is therefore not that information beyond headline GDP growth does not provide additional value-added when dating business cycles. It is simply that our reconciled measures of true GDP are the most informative single measure - with a clear "economic interpretation". As made in Mariano and Murasawa (2003), an argument for measures of GDP itself, rather than construction of indices of economic activity, is that the size of movements in GDP has a direct economic interpretation, in contrast to the levels of indices. A further advantage is that, once a quarter when aggregated, measures of monthly $G D P$, at least as measured by $G D P_{I}$ or $G D P_{E}$, can be evaluated through comparison with the BEA's own quarterly estimates.

\subsubsection{Real-time recession probabilities: looking back at the 2007-2009 recession}

To showcase the use of our models in real-time we revisit the 2007-2009 recession, as identified by the NBER, and assess our models' ability - when used monthly as if in real-time - to date this recession. The NBER classify the recession, due to the global financial crisis, as starting in January 2008 and ending in June 2009. As Nalewaik (2012) has emphasized, GDP $P_{I}$ has a track-record of detecting recessions earlier than $G D P_{E}$, although it is published more slowly. This raises the possibility that a model exploiting and reconciling both $G D P_{E}$ and $G D P_{I}$, along with additional monthly indicator variables as they accrue in real-time, may be better able to anticipate recessions.

To mimic use of these models in real-time, for all these monthly variables and in all our models we make use of the real-time monthly data vintages. And we acknowledge the staggered release of data in real-time (the so-called ragged-edge) due to differing publication lags. These monthly variables

\footnotetext{
${ }^{21}$ The AUC statistics are compared using DeLong et al. (1988)'s test as implemented in the R package, pROC In online Appendix C, Table 17, we show that true GDP also yields higher AUC values when we date the business cycle not using the recession probability estimates computed across MCMC draws but using the posterior mean estimates of GDP. Table 17 also shows this result to be robust to which of the seven models of Table 3 we consider.

${ }^{22}$ As explained above, in Table 9 we analyze the ADS index when aggregated to represent quarter-on-quarter annualized growth rates. When analyzed in its underlying and original form, the ADS index achieves an AUC statistic of 0.99 (standard error of 0.007 ).
} 


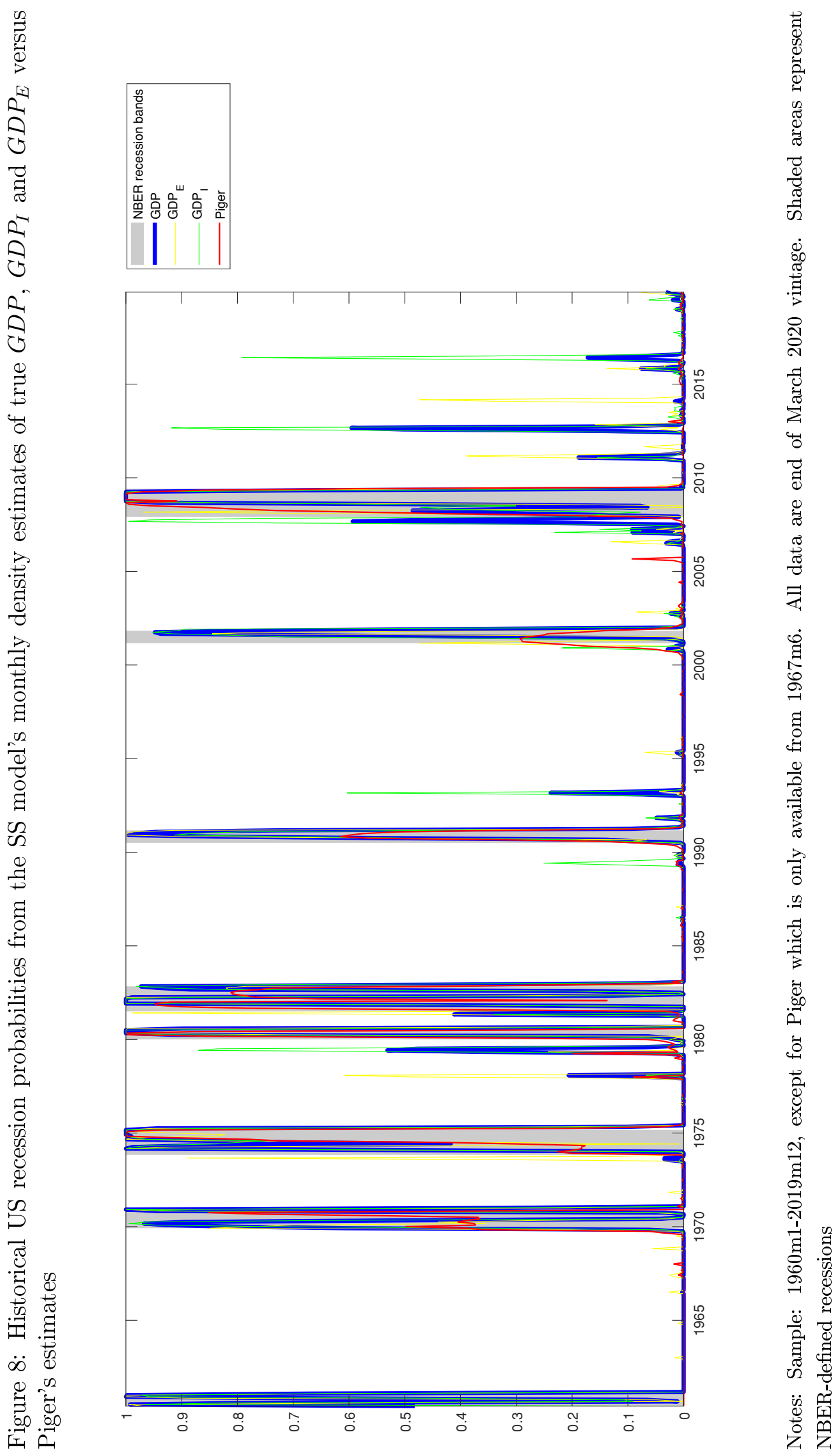


Table 9: Business cycles features: Classification ability of the monthly GDP estimates from the SS MF-VAR model compared with the Brave, Butters and Kelley (BBK) coincident index and monthly GDP (MGDP) estimates, estimates maintained by Jeremy Piger and a monthly aggregation of the Aruoba, Diebold and Scotti (ADS) index. Area under the receiver operating characteristic curve (AUC) values and threshold estimates that optimize classification ability when hits and misses are given equal weight

\begin{tabular}{cccccc}
\hline \hline Variables & SS & BBK: MGDP & Piger & BBK: Index & ADS \\
\hline \multicolumn{5}{c}{ AUC estimates } \\
\hline True $G D P$ & 0.94 & & & \\
& $(0.018)$ & & & \\
\hline$G D P_{E}$ & 0.92 & 0.92 & 0.99 & 0.99 & 0.96 \\
& $(0.020)$ & $(0.020)$ & $(0.003)$ & $(0.008)$ & $(0.014)$ \\
\hline$G D P_{I}$ & 0.92 & & & & \\
& $(0.020)$ & & & \\
\hline
\end{tabular}

\section{Optimal threshold parameter}

\begin{tabular}{cccccc}
\hline True $G D P$ & $40 \%$ & & & & \\
\hline$G D P_{E}$ & $76 \%$ & -1.24 & $91 \%$ & -0.76 & -2.05 \\
\hline$G D P_{I}$ & $63 \%$ & & & & \\
\hline \hline
\end{tabular}

Notes: Sample: 1960m1-2019m12, except for Piger which is only available from 1967m6. Standard errors reported in parentheses. The BBK Index and ADS are not to be interpreted as direct estimates of monthly GDP as they are broader indices of economic activity.

are aligned with real-time monthly data vintages of quarterly $G D P_{I}$ and $G D P_{E}$. Data vintages are organized so that our recession probability estimates for month $t$ are produced near the end of month $t+1$, using monthly and quarterly indicator data available at this point in time. Given $G D P_{I}$ data are published more slowly than $G D P_{E}$, this means that in the first month of each calendar quarter while the last quarter's $G D P_{E}$ estimate is known, the BEA has yet to publish $G D P_{I}$.

We estimate the seven models of Table 3 recursively from January 2007 through December 2009 and produce estimates of true monthly $G D P, y_{t}^{Q}$. For each MCMC draw, as in the historical business cycle analysis but now focusing on true $G D P$ to again facilitate cross-model comparisons, we compute recession probabilities by comparing $y_{t}^{Q}$ with the optimal estimates $c$. To acknowledge the fact that the NBER announce recessions with at least a 12 month lag, when using this strategy to classify in real-time whether $y_{t}^{Q}$ is a recession or not, we only use NBER data up to month $t-12$ to estimate $c$. We note how the estimates for $c$ are recursively updated through our out-of-sample window.

Figure 9 plots the recursively computed estimates of a recession in month $t$ from each of the seven 
models from January 2007 through December 2009. Alongside, for comparison, we plot the real-time recession probability estimates maintained by Jeremy Piger ${ }^{23}$ These estimates are real-time and exploit the vintage data maintained by Piger. We note that, over this period, Piger's recessionary estimates for month $t$ are produced not near the end of month $t+1$, but a month later and so have an informational advantage (or timing disadvantage) relative to our estimates.

Figure 9 reveals that all of our models identify increasing recessionary risks from the beginning of 2008, well ahead of the NBER announcing in December 2008 that the recession did begin in January 2008. But, especially for the smaller SS models, there are (according to the NBER) false recessionary signals in mid 2007, with a local spike in the recession probabilities. This spike is driven by the negative estimates for true monthly GDP growth seen in Figure 5 (for the SS model) in May 2007, explained by larger negative estimates for $G D P_{I}$. Interestingly, the Big Data SS model (SS+) down weights the odds of a recession in mid 2007. The recessionary probabilities from all the models do not approach unity until almost a year later, when the NBER do classify a recession. And they decline sharply from June 2009, well ahead of the NBER (in late September 2010) classifying June 2009 as the final month of the recession.

Again we conclude from this real-time exercise that our monthly estimates of true GDP do a good job of tracking NBER business cycles out-of-sample, as well as in-sample. Indeed, visually Figure 9 provides some evidence that these estimates of true GDP provide a sharper signal of the recession than Piger's real-time recession probabilities. Piger's estimates spike before the beginning of the recession and then fall more slowly at its conclusion. We also appear to find more variation across our models out-of-sample than in-sample. Conditioning on the published quarterly estimates of $G D P_{I}$ and $G D P_{E}$ from the BEA disciplines our models' monthly GDP estimates in-sample and helps explain their similarities. But out-of-sample, absent knowledge of these quarterly realizations, the monthly indicator variables appear to play a heightened role in shaping the probabilistic path of true $G D P$.

We emphasize that Figure 9 shows the real-time recession probabilities from our models. Arguably these are of most interest to policymakers, making decisions without the benefit of hindsight or revised data. But comparison against the full-sample (final vintage) recession probability estimates (cf. Figure 8) indicates the unreliability (in the sense of Orphanides and van Norden (2002)) of these real-time estimates. Data revisions explain much of this; e.g., as we move across data vintages, the 2007q4 estimate of $G D P_{E}$ switches from being a positive, to a negative, and back to a positive growth rate

\footnotetext{
${ }^{23}$ See https: //pages .uoregon.edu/jpiger/us_recession_probs.htm/
} 
relative to $2007 \mathrm{q} 3$. Indeed, the April 302020 vintage data ${ }^{24}$ show that while the $2007 \mathrm{q} 4$ value of real $G D P_{E}$ is higher than the $2007 \mathrm{q} 3$ value, the reverse holds for $G D P_{I}$. This is an additional reason why we might be uncertain as to whether "true" GDP was expanding during 2007q4: the two BEA estimates of $G D P$ disagree.

Figure 9: Real-time recession probabilities over the period of the global financial crisis from the seven models of Table 3 compared against Piger's real-time estimates

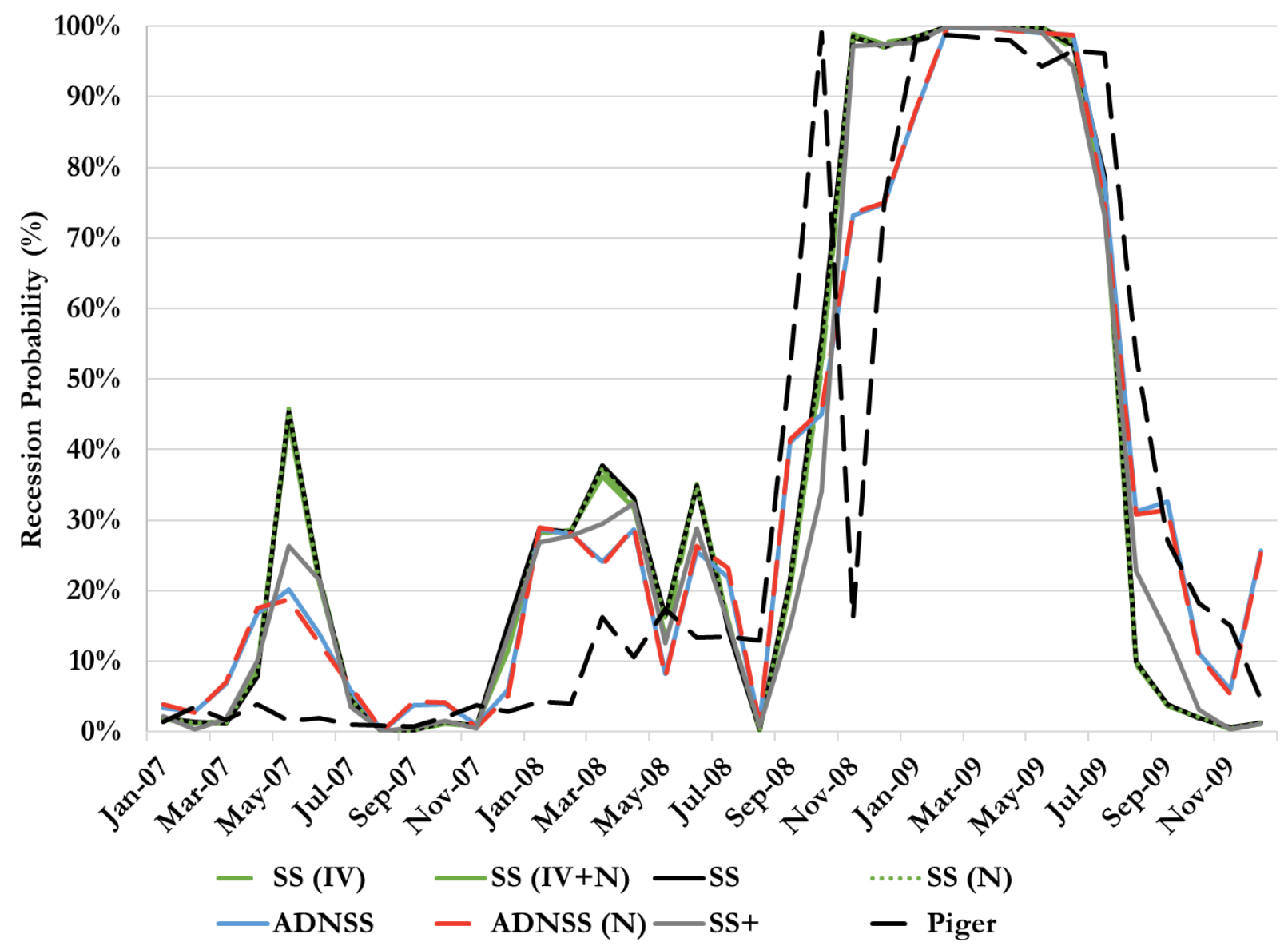

\subsubsection{Coronavirus pandemic update}

Finally, given the emerging (at the time of writing) recession due to the Covid-19 pandemic lockdown of 2020, we update our historical monthly estimates of true GDP given monthly and quarterly data through the first half of 2020 (this includes $2020 \mathrm{q} 2$ data on $G D P_{I}$ and $G D P_{E}$ ). This serves as a

\footnotetext{
${ }^{24}$ Available at https://apps.bea.gov/histdata/fileStructDisplay.cfm?HMI=7\&DY=2020\&DQ=Q1\&DV=Advance\& dNRD=April $-30-2020$
} 
real-time test of the robustness of our historical estimates. Despite the extreme observations seen in 2020, we find the historical estimates of monthly reconciled GDP from 1960m1 through $2019 \mathrm{~m} 12$ from the SS model estimated on the augmented sample to be virtually identical to those seen in Figure 5. That is, re-estimating the SS model on augmented data through the first half of 2020 does not change the historical path of true GDP (the posterior median estimates are correlated 0.98 over the common sample up to $2019 \mathrm{~m} 12$ ). This stability, in comparison to recent evidence showing that parameter estimates from MF-VAR models can change abruptly in the face of extreme observations and that nowcasts and forecasts can be affected (e.g. see Schorfheide and Song (2020) and Lenza and Primiceri (2020)), will be due to the structure imposed via the measurement error model of ADNSS and the temporal aggregation constraint, (7). Diagnostic tests for the Normality assumption for the disturbances $\epsilon_{G t}, \epsilon_{E t}$ and $\epsilon_{I t}$ only slightly deteriorate when we include the pandemic observations. These have p-values for the Kolomogorov-Smirnov Normality tests of $0.13,0.17$ and 0.02 , respectively, using data through 2019. Adding the pandemic observations, led to these falling to $0.02,0.11$ and 0.02 , respectively.

\section{Conclusions}

$G D P$ remains the most informative and readily interpretable single measure of economic activity. But its measurement, in the US at least, arguably is confused by separate and disparate point estimates from the BEA on the expenditure and income sides. $G D P_{E}$ and $G D P_{I}$ can and often do differ, and in economically important ways. Moreover, the quarterly frequency of the BEA's estimates impedes both historical economic analysis, such as the within-quarter impact of historical events, and timely tracking of the evolution of the economic activity. Accordingly, this paper embeds the quarterly $G D P_{E}$ and $G D P_{I}$ data reconciliation model of ADNSS within a Bayesian MF-VAR model

with temporal aggregation constraints. The argument for reconciliation, not just of quarterly $G D P_{E}$ and $G D P_{I}$ data but also for exploiting the wealth of monthly indicators that take the pulse of the economy, is that the reconciled monthly GDP estimates incorporate more information. And unlike index based measures of economic activity, estimates of monthly GDP have a natural interpretation; when aggregated to the quarterly frequency, they can be compared (and evaluated) directly against the BEA's own estimates.

Having explained identification and prior elicitation issues, and established the validity of the proposed Bayesian approach, we estimate different variants of the model to produce reconciled historical 
estimates of monthly GDP, and its uncertainty, from 1960 to the present day. These new reconciled estimates of monthly $G D P$ are consistent with the BEA's published quarterly estimates of $G D P_{E}$ and $G D P_{I}$; but they exploit within-quarter information about economic activity gleaned from many monthly indicator variables. Our new monthly reconciled GDP estimates confirm the quarterly findings in Nalewaik (2010) and ADNSS that $G D P_{I}$ contributes more to true GDP measurement than the more commonly used $G D P_{E}$.

We find that historical estimates of reconciled monthly GDP are robust to specific modeling choices, such as over the set of monthly variables to include in the model and how identification is achieved. Our new monthly reconciled density estimates of true GDP are found to better align with historical US business cycles than separate estimates of $G D P_{E}$ and $G D P_{I}$. Out-of-sample, in a real-time case study revisiting the 2007-9 recession, we further illustrate the utility of our monthly $G D P$ density estimates at tracking the US business cycle in the face of staggered data releases, acknowledging that quarterly $G D P_{I}$ data are published by the BEA at a lag to their estimates of $G D P_{E}$. Finally, and reassuringly, we find that our historical estimates of monthly $G D P$ are largely unaffected when we update our sample to include the 2020 pandemic period and its extreme data realizations.

Interesting extensions of our model will involve using it in real-time to produce monthly density nowcast and forecasts, including of $G D P_{E}$ and $G D P_{I}$, noting that once a quarter these nowcasts and forecasts can be evaluated relative to the quarterly realizations of $G D P_{E}$ and $G D P_{I}$ subsequently published by the BEA. Following Jacobs et al. (2018), this could also involve exploiting the revisions properties of $G D P$ estimates by modeling multiple data vintages. 


\section{References}

[1] Aruoba, S., Diebold, F., Nalewaik, J., Schorfheide, F. and Song, D. (2016). Improving GDP measurement: A measurement-error perspective. Journal of Econometrics, 191, 384-397.

[2] Aruoba, S., Diebold, F. and Scotti, C. (2009). Real-Time Measurement of Business Conditions. Journal of Business and Economic Statistics, 27, 417-27.

[3] Berge, T.J. and Jorda, O. (2011). Evaluating the classification of economic activity into recessions and expansions. American Economic Journal: Macroeconomics, 3, 246-277.

[4] Brave, S., Butters, R. and Kelley, D. (2019). A new "big data" index of U.S. economic activity. Economic Perspectives, Federal Reserve Bank of Chicago, 43. Available at https://www.chicagofed.org/publications/economic-perspectives/2019/1

[5] Brave, S., Butters, R. and Justiniano, A. (2019). Forecasting economic activity with mixed frequency Bayesian VARs. International Journal of Forecasting, 35, 1692-1707.

[6] Carriero, A., Clark, T., and Marcellino, M. (2019). Large Bayesian vector autoregressions with stochastic volatility and non-conjugate priors. Journal of Econometrics 212, 137-154.

[7] Chang, A.C. and Li, P. (2018). Measurement error in macroeconomic data and economics research: data revisions, Gross Domestic Product, and Gross Domestic Income. Economic Inquiry, $56,1846-1869$.

[8] Chauvet, M. (1998). An econometric characterization of business cycle dynamics with factor structure and regime switches. International Economic Review, 39, 969-996.

[9] Chauvet, M. and Piger, J. (2008). A comparison of the real-time performance of business cycle dating methods. Journal of Business and Economic Statistics, 26, 42-49.

[10] DeLong, E., DeLong, D. and Clarke-Pearson, D. (1988). Comparing the areas under two or more correlated receiver operating characteristic curves: a nonparametric approach. Biometrics, 44, $837-845$.

[11] Eraker, B., Chiu, C., Foerster, A., Kim, T. and Seoane, H. (2015). Bayesian mixed frequency VAR's. Journal of Financial Econometrics, 13, 698-721. 
[12] Fixler, D.J. and Nalewaik, J. (2010). News, noise, and estimates of the "true" unobserved state of the economy. BEA Working Papers 0068, Bureau of Economic Analysis.

[13] Garciga, C. and Knotek II, E.S. (2019). Forecasting GDP growth with NIPA aggregates: in search of core GDP. International Journal of Forecasting, 35, 1814-1828.

[14] Jacobs, J.P.A.M., Sarferaz, S., Sturm, J.-E. and van Norden, S. (2018). Can GDP measurement be further improved? Data revision and reconciliation. Economic Statistics Centre of Excellence (ESCoE) Discussion Papers, ESCoE DP-2018-15.

[15] Kastner, G. and Huber, F. (2020). Sparse Bayesian Vector Autoregressions in huge dimensions. Journal of Forecasting, forthcoming.

[16] Koop, G., McIntyre, S., Mitchell, J. and Poon, A. (2020). Regional output growth in the United Kingdom: More timely and higher frequency estimates from 1970. Journal of Applied Econometrics, 35, 176-197.

[17] Lenza, M. and Primiceri, G. (2020). How to estimate a VAR after March 2020. Manuscript.

[18] Mankiw, N.G. and Shapiro, M.D. (1986). News or noise: an analysis of GNP Revisions. Survey of Current Business, May, 20-25.

[19] Mariano, R. and Murasawa, Y. (2003). A new coincident index of business cycles based on monthly and quarterly series. Journal of Applied Econometrics. 18, 427-443.

[20] Mariano, R. and Murasawa, Y. (2010). A coincident index, common factors, and monthly real GDP. Oxford Bulletin of Economics and Statistics. 72, 27-46.

[21] McCracken, M. and Ng, S. (2016). FRED-MD: A monthly database for macroeconomic research. Journal of Business and Economic Statistics, 34, 574-589.

[22] Mitchell, J., Smith, R., Weale, M., Wright, S. and Salazar, E. (2005). An indicator of monthly GDP and an early estimate of quarterly GDP growth. Economic Journal, 115, 108-129.

[23] Nalewaik, J.J. (2010). The income- and expenditure-side estimates of U.S. output growth. Brookings Papers on Economic Activity, 1, 71-127 (with discussion).

[24] Nalewaik, J.J. (2012). Estimating probabilities of recession in real time using GDP and GDI. Journal of Money, Credit and Banking, 44, 235-253. 
[25] Orphanides, A. and van Norden, S. (2002). The unreliability of output-gap estimates in real time. Review of Economics and Statistics, 84(4), 569-583.

[26] Poirier, D. (1998). Revising beliefs in non-identified models. Econometric Theory, 14, 483-509.

[27] Schorfheide, F. and Song, D. (2015). Real-time forecasting with a mixed-frequency VAR. Journal of Business and Economic Statistics, 33(3), 366-380.

[28] Schorfheide, F. and Song, D. (2020). Real-time forecasting with a (standard) mixed-frequency VAR during a pandemic. Manuscript.

[29] Stock, J.H. and Watson, M.W. (2014). Estimating turning points using large data sets. Journal of Econometrics, 178, 368-381.

[30] Stone, R., Champernowne, D.G. and Meade, J.E. (1942). The precision of national income estimates. Review of Economic Studies, 9, 111-125.

[31] Weale, M. (1985). Testing linear hypotheses on national account data. Review of Economics and Statistics, 67, 685-689. 


\section{A Online Appendices}

\section{A.1 Model Details and Priors}

\section{A.1.1 Prior for quarterly VAR containing only GDP variables}

The following prior is bounded to ensure $0.55<\xi_{E}, \xi_{I}<1.15$

1. $a_{21}, a_{31}, a_{32} \sim N(0,10)$.

2. $\mu \sim N(0,100), b_{11} \sim N(0,10)$.

3. $\sigma_{G G}^{2}, \sigma_{E E}^{2}, \sigma_{I I}^{2} \sim I G(3.8,8.4)$ - The inverse gamma prior mean is 3 and variance is 5 .

\section{A.1.2 Prior for quarterly VAR containing unemployment and GDP variables}

The following prior is bounded to ensure $0.55<\xi_{E}, \xi_{I}<1.15$

1. $a_{21} \sim N(0.5,1), a_{32}, a_{42} \sim N(-1,0.1)$ and $a_{43} \sim N(0,1)$.

2. $\mu, \mu_{b} \sim N(0,100), b_{11}, b_{12}, b_{21}, b_{22} \sim N(0,10)$.

3. $\sigma_{U U}^{2}, \sigma_{G G}^{2}, \sigma_{E E}^{2}, \sigma_{I I}^{2} \sim I G(3.8,8.4)$ - The inverse gamma prior mean is 3 and variance is 5 .

\section{A.1.3 Choice for $A$ and priors for MF-VAR containing GDP variables, unemployment and other monthly variables}

Our MF-VARs contain the GDP variables and the same eight monthly variables as in Schorfheide and Song (2015). The monthly variables are a measure of hours worked $\left(a w h_{t}\right)$, inflation $\left(\pi_{t}\right)$, industrial production $\left(i p_{t}\right)$, personal consumption expenditures $\left(p e_{t}\right)$, short term interest rates $\left(r_{t}\right)$, long term interest rates $\left(r_{t}^{G S 10}\right)$, stock prices $\left(s t_{t}\right)$ and the unemployment rate $\left(U_{t}\right)$. Exact definitions and data transformations are given below in the Data Appendix.

The part of $B$ defining a VAR for true GDP and these monthly variables is unrestricted. The part of $B$ relating to the relationship between $G D P_{E}, G D P_{I}$ and true GDP is restricted as in Sub-section 4.2 of the paper. 


\section{A.1.4 Model which imposes restriction that all monthly variables are instruments}

The left-hand side of the MF-VAR for this model takes the following form:

$$
\left[\begin{array}{ccccccccccc}
1 & 0 & 0 & 0 & 0 & 0 & 0 & 0 & 0 & 0 & 0 \\
a_{21} & 1 & 0 & 0 & 0 & 0 & 0 & 0 & 0 & 0 & 0 \\
a_{31} & a_{32} & 1 & 0 & 0 & 0 & 0 & 0 & 0 & 0 & 0 \\
a_{41} & a_{42} & a_{43} & 1 & 0 & 0 & 0 & 0 & 0 & 0 & 0 \\
a_{51} & a_{52} & a_{53} & a_{54} & 1 & 0 & 0 & 0 & 0 & 0 & 0 \\
a_{61} & a_{62} & a_{63} & a_{64} & a_{65} & 1 & 0 & 0 & 0 & 0 & 0 \\
a_{71} & a_{72} & a_{73} & a_{74} & a_{75} & a_{76} & 1 & 0 & 0 & 0 & 0 \\
a_{81} & a_{82} & a_{83} & a_{84} & a_{85} & a_{86} & a_{87} & 1 & 0 & 0 & 0 \\
a_{91} & a_{92} & a_{93} & a_{94} & a_{95} & a_{96} & a_{97} & a_{98} & 1 & 0 & 0 \\
0 & 0 & 0 & 0 & 0 & 0 & 0 & 0 & a_{109} & 1 & 0 \\
0 & 0 & 0 & 0 & 0 & 0 & 0 & 0 & a_{119} & a_{1110} & 1
\end{array}\right]\left[\begin{array}{c}
a w h_{t} \\
\pi_{t} \\
i p_{t} \\
p c e_{t} \\
r_{t} \\
r_{t}^{G S 10} \\
s t_{t} \\
U_{t} \\
G D P_{t} \\
G D P_{E, t} \\
G D P_{I, t}
\end{array}\right]
$$

We use notation where $\hat{a}=\left(a_{21}, a_{31}, \ldots, a_{95}, a_{98}\right)^{\prime}$ and $\tilde{a}$ are all the remaining coefficients in $A$,

all the free coefficients in $B$ and the intercepts in the MF-VAR. $\sigma_{i i}^{2}$ denotes the error variance in equation $i$. The prior is:

1. $a_{109}, a_{119} \sim N(-1,0.1)$ and $a_{1110} \sim N(0,1)$.

2. $\tilde{a} \sim D L(\alpha)-\alpha$ is the hyperparameter on the DL priors and is set to $\alpha=0.5$.

3. $\hat{a} \sim D L(\bar{\alpha})-\bar{\alpha}$ is the hyperparameter on the DL priors and is set to $\bar{\alpha}=0.5$.

4. $\sigma_{i i}^{2} \sim \operatorname{IG}(5, .01)$.

The prior is bounded to ensure $0.55<\xi_{E}, \xi_{I}<1.15$.

Model which imposes noise restriction and the restriction that all monthly variables are instruments

The left-hand side of the MF-VAR for this model takes the following form: 


$$
\left[\begin{array}{ccccccccccc}
1 & 0 & 0 & 0 & 0 & 0 & 0 & 0 & 0 & 0 & 0 \\
a_{21} & 1 & 0 & 0 & 0 & 0 & 0 & 0 & 0 & 0 & 0 \\
a_{31} & a_{32} & 1 & 0 & 0 & 0 & 0 & 0 & 0 & 0 & 0 \\
a_{41} & a_{42} & a_{43} & 1 & 0 & 0 & 0 & 0 & 0 & 0 & 0 \\
a_{51} & a_{52} & a_{53} & a_{54} & 1 & 0 & 0 & 0 & 0 & 0 & 0 \\
a_{61} & a_{62} & a_{63} & a_{64} & a_{65} & 1 & 0 & 0 & 0 & 0 & 0 \\
a_{71} & a_{72} & a_{73} & a_{74} & a_{75} & a_{76} & 1 & 0 & 0 & 0 & 0 \\
a_{81} & a_{82} & a_{83} & a_{84} & a_{85} & a_{86} & a_{87} & 1 & 0 & 0 & 0 \\
a_{91} & a_{92} & a_{93} & a_{94} & a_{95} & a_{96} & a_{97} & a_{98} & 1 & 0 & 0 \\
0 & 0 & 0 & 0 & 0 & 0 & 0 & 0 & -1 & 1 & 0 \\
0 & 0 & 0 & 0 & 0 & 0 & 0 & 0 & -1-a_{1110} & a_{1110} & 1
\end{array}\right]\left[\begin{array}{c}
a w h_{t} \\
\pi_{t} \\
i p_{t} \\
p c e_{t} \\
r_{t} \\
r_{t}^{G S 10} \\
s t_{t} \\
U_{t} \\
G D P_{t} \\
G D P_{E, t} \\
G D P_{I, t}
\end{array}\right]
$$

We use notation where $\hat{a}=\left(a_{21}, a_{31}, \ldots, a_{95}, a_{98}\right)^{\prime}$ and $\tilde{a}$ are all the remaining coefficients in $A$, all the free coefficients in $B$ and the intercepts in the MF-VAR. $\sigma_{i i}^{2}$ denotes the error variance in equation $i$. The prior is:

1. $a_{1110} \sim N(0,1)$.

2. $\tilde{a} \sim D L(\alpha)-\alpha$ is the hyperparameter on the DL priors and is set to $\alpha=0.5$.

3. $\hat{a} \sim D L(\bar{\alpha})-\bar{\alpha}$ is the hyperparameter on the DL priors and is set to $\bar{\alpha}=0.5$.

4. $\sigma_{i i}^{2} \sim \operatorname{IG}(5, .01)$.

The prior is bounded to ensure $0.55<\xi_{E}, \xi_{I}<1.15$.

Model which only imposes the restriction that unemployment is an instrument

The left-hand side of the MF-VAR for this model takes the following form: 


$$
\left[\begin{array}{ccccccccccc}
1 & 0 & 0 & 0 & 0 & 0 & 0 & 0 & 0 & 0 & 0 \\
a_{21} & 1 & 0 & 0 & 0 & 0 & 0 & 0 & 0 & 0 & 0 \\
a_{31} & a_{32} & 1 & 0 & 0 & 0 & 0 & 0 & 0 & 0 & 0 \\
a_{41} & a_{42} & a_{43} & 1 & 0 & 0 & 0 & 0 & 0 & 0 & 0 \\
a_{51} & a_{52} & a_{53} & a_{54} & 1 & 0 & 0 & 0 & 0 & 0 & 0 \\
a_{61} & a_{62} & a_{63} & a_{64} & a_{65} & 1 & 0 & 0 & 0 & 0 & 0 \\
a_{71} & a_{72} & a_{73} & a_{74} & a_{75} & a_{76} & 1 & 0 & 0 & 0 & 0 \\
a_{81} & a_{82} & a_{83} & a_{84} & a_{85} & a_{86} & a_{87} & 1 & 0 & 0 & 0 \\
a_{91} & a_{92} & a_{93} & a_{94} & a_{95} & a_{96} & a_{97} & a_{98} & 1 & 0 & 0 \\
a_{101} & a_{102} & a_{103} & a_{104} & a_{105} & a_{106} & a_{107} & 0 & a_{109} & 1 & 0 \\
a_{111} & a_{112} & a_{113} & a_{114} & a_{115} & a_{116} & a_{117} & 0 & a_{119} & a_{1110} & 1
\end{array}\right]\left[\begin{array}{c}
a w h_{t} \\
\pi_{t} \\
i p_{t} \\
p c e_{t} \\
r_{t} \\
r_{t}^{G S 10} \\
s t_{t} \\
U_{t} \\
G D P_{t} \\
G D P_{E, t} \\
G D P_{I, t}
\end{array}\right]
$$

We use notation where $\hat{a}=\left(a_{21}, a_{31}, \ldots, a_{116}, a_{117}\right)^{\prime}$ and $\tilde{a}$ are all the remaining coefficients in $A$, all the free coefficients in $B$ and the intercepts in the MF-VAR. $\sigma_{i i}^{2}$ denotes the error variance in equation $i$. The prior is:

1. $a_{109}, a_{119} \sim N(-1,0.1)$ and $a_{1110} \sim N(0,1)$.

2. $\tilde{a} \sim D L(\alpha)-\alpha$ is the hyperparameter on the DL priors and is set to $\alpha=0.5$.

3. $\hat{a} \sim D L(\bar{\alpha})-\bar{\alpha}$ is the hyperparameter on the DL priors and is set to $\bar{\alpha}=0.5$.

4. $\sigma_{i i}^{2} \sim \operatorname{IG}(5, .01)$.

The prior is bounded to ensure $0.55<\xi_{E}, \xi_{I}<1.15$.

Model which imposes the noise restriction and the restriction that unemployment is an instrument

The left-hand side of the MF-VAR for this model takes the following form: 


$$
\left[\begin{array}{ccccccccccc}
1 & 0 & 0 & 0 & 0 & 0 & 0 & 0 & 0 & 0 & 0 \\
a_{21} & 1 & 0 & 0 & 0 & 0 & 0 & 0 & 0 & 0 & 0 \\
a_{31} & a_{32} & 1 & 0 & 0 & 0 & 0 & 0 & 0 & 0 & 0 \\
a_{41} & a_{42} & a_{43} & 1 & 0 & 0 & 0 & 0 & 0 & 0 & 0 \\
a_{51} & a_{52} & a_{53} & a_{54} & 1 & 0 & 0 & 0 & 0 & 0 & 0 \\
a_{61} & a_{62} & a_{63} & a_{64} & a_{65} & 1 & 0 & 0 & 0 & 0 & 0 \\
a_{71} & a_{72} & a_{73} & a_{74} & a_{75} & a_{76} & 1 & 0 & 0 & 0 & 0 \\
a_{81} & a_{82} & a_{83} & a_{84} & a_{85} & a_{86} & a_{87} & 1 & 0 & 0 & 0 \\
a_{91} & a_{92} & a_{93} & a_{94} & a_{95} & a_{96} & a_{97} & a_{98} & 1 & 0 & 0 \\
a_{101} & a_{102} & a_{103} & a_{104} & a_{105} & a_{106} & a_{107} & 0 & -1 & 1 & 0 \\
a_{111} & a_{112} & a_{113} & a_{114} & a_{115} & a_{116} & a_{117} & 0 & -1-a_{1110} & a_{1110} & 1
\end{array}\right]\left[\begin{array}{c}
a w h_{t} \\
\pi_{t} \\
i p_{t} \\
p c e_{t} \\
r_{t} \\
r_{t}^{G S 10} \\
s t_{t} \\
U_{t} \\
G D P_{t} \\
G D P_{E, t} \\
G D P_{I, t}
\end{array}\right]
$$

We use notation where $\hat{a}=\left(a_{21}, a_{31}, \ldots, a_{116}, a_{117}\right)^{\prime}$ and $\tilde{a}$ are all the remaining coefficients in $A$, all the free coefficients in $B$ and the intercepts in the MF-VAR. $\sigma_{i i}^{2}$ denotes the error variance in equation $i$. The prior is:

1. $a_{1110} \sim N(0,1)$.

2. $\tilde{a} \sim D L(\alpha)-\alpha$ is the hyperparameter on the DL priors and is set to $\alpha=0.5$.

3. $\hat{a} \sim D L(\bar{\alpha})-\bar{\alpha}$ is the hyperparameter on the DL priors and is set to $\bar{\alpha}=0.5$.

4. $\sigma_{i i}^{2} \sim \operatorname{IG}(5, .01)$.

The prior is bounded to ensure $0.55<\xi_{E}, \xi_{I}<1.15$.

\section{A.2 MCMC Algorithm without Mixed Frequencies}

In this section, we provide the details of the MCMC algorithm for the quarterly model with a single quarterly predictor. This algorithm can be easily extended to the models with many additional variables. Specifically, we can expand equation (1) of the paper as: 


$$
\left[\begin{array}{cccc}
1 & 0 & 0 & 0 \\
a_{21} & 1 & 0 & 0 \\
0 & a_{32} & 1 & 0 \\
0 & a_{42} & a_{43} & 1
\end{array}\right]\left[\begin{array}{c}
U_{t} \\
G D P_{t} \\
G D P_{E, t} \\
G D P_{I, t}
\end{array}\right]=\left[\begin{array}{c}
\mu_{U E} \\
\mu_{G D P} \\
0 \\
0
\end{array}\right]+\left[\begin{array}{cccc}
b_{11} & b_{12} & 0 & 0 \\
b_{21} & b_{22} & 0 & 0 \\
0 & 0 & 0 & 0 \\
0 & 0 & 0 & 0
\end{array}\right]\left[\begin{array}{c}
U_{t-1} \\
G D P_{t-1} \\
G D P_{E, t-1} \\
G D P_{I, t-1}
\end{array}\right]+\left[\begin{array}{c}
\epsilon_{U, t} \\
\epsilon_{G, t} \\
\epsilon_{E, t} \\
\epsilon_{I, t}
\end{array}\right],
$$

where

$$
\left[\begin{array}{c}
\epsilon_{U, t} \\
\epsilon_{G, t} \\
\epsilon_{E, t} \\
\epsilon_{I, t}
\end{array}\right] \sim N\left(\left[\begin{array}{l}
0 \\
0 \\
0 \\
0
\end{array}\right],\left[\begin{array}{cccc}
\sigma_{U U}^{2} & 0 & 0 & 0 \\
0 & \sigma_{G G}^{2} & 0 & 0 \\
0 & 0 & \sigma_{E E}^{2} & 0 \\
0 & 0 & 0 & \sigma_{I I}^{2}
\end{array}\right]\right)
$$

The preceding sub-section described the priors for $A$ and the error variances. For the remaining parameters and initial conditions, we make relatively non-informative choices of: $\mu_{U E}, \mu_{G D P} \sim N\left(0, V_{4}\right)$, $b_{11}, b_{12}, b_{21}, b_{22} \sim N\left(0, V_{5}\right), G D P_{1} \sim N\left(0, V_{G D P}\right)$ and $\sigma_{i i}^{2} \sim I G(\nu, S)$. We set the following hyperparameters: $V_{4}=100, V_{5}=10, V_{G D P}=10, \nu=3.8$ and $S=8.4$. We can use the equation by equation method of Carriero et al. (2019) to sample all the parameters, and the Gibbs sampler is specified below. Note, for the models with more monthly variables, we use Dirichlet-Laplace (DL) priors on the VAR coefficients and covariance terms. Since this prior is conditionally Normal, the Gibbs sampler described below is mostly unchanged. All that is required are the additional steps to draw the DL parameters and this is carried out as detailed in the appendix of Koop et al. (2020).

\section{A.3 Sample $U_{t}$ equation}

We can rewrite the first equation of the VAR in $(9)$ as:

$$
\mathbf{U}=\mathbf{X} \beta+\epsilon_{U}, \epsilon_{U} \sim N\left(0, \sigma_{U U}^{2} \mathbf{I}_{T}\right)
$$

where

$$
\mathbf{X}=\left[\begin{array}{ccc}
1 & U_{0} & 0 \\
1 & U_{1} & G D P_{1} \\
\vdots & \vdots & \vdots \\
1 & U_{T-1} & G D P_{T-1}
\end{array}\right]
$$

Let $\mathbf{U}=\left(U_{1}, \ldots, U_{T}\right)^{\prime}$ and $\beta=\left(\mu_{U E}, b_{11}, b_{12}\right)^{\prime}$. Combining 11 with the above specified priors and using the simple Bayesian linear regression formula, the conditional posterior for $\beta$ is: 


$$
\beta \mid \bullet \sim N\left(\hat{\beta}, \mathbf{K}_{\beta}\right)
$$

where $\mathbf{S}_{1}=\operatorname{diag}\left(V_{4}, V_{5}, V_{5}\right)$ and

$$
\mathbf{K}_{\beta}=\left(\frac{\mathbf{X}^{\prime} \mathbf{X}}{\sigma_{U U}^{2}}+\mathbf{S}_{1}^{-1}\right)^{-1}, \quad \hat{\beta}=\mathbf{K}_{\beta}\left(\frac{\mathbf{X}^{\prime} \mathbf{U}}{\sigma_{U U}^{2}}\right) .
$$

Finally, the conditional posterior for $\sigma_{U U}^{2}$ is

$$
\sigma_{U U}^{2} \mid \bullet \sim I G\left(\nu+\frac{T}{2}, S+\frac{(\mathbf{U}-\mathbf{X} \beta)^{\prime}(\mathbf{U}-\mathbf{X} \beta)}{2}\right) .
$$

\section{A.4 Sample $G D P_{t}$ equation}

We can rewrite the second equation of the VAR in (9) as

$$
G D P=\mathbf{Z} \theta+\epsilon_{G}, \epsilon_{G} \sim N\left(0, \sigma_{G G}^{2} \mathbf{I}_{T}\right),
$$

where

$$
\mathbf{Z}=\left[\begin{array}{cccc}
1 & U_{1} & G D P_{1} & -U_{2} \\
1 & U_{2} & G D P_{2} & -U_{3} \\
\vdots & \vdots & \vdots & \vdots \\
1 & U_{T-1} & G D P_{T-1} & -U_{T}
\end{array}\right]
$$

Let $G D P=\left(G D P_{2}, \ldots, G D P_{T}\right)^{\prime}$ and $\theta=\left(\mu_{G D P}, b_{21}, b_{22}, a_{21}\right)^{\prime}$. Combining (14) with the above specified priors and using the simple Bayesian linear regression formula, the conditional posterior for $\theta$ is:

$$
\theta \mid \bullet \sim N\left(\hat{\theta}, \mathbf{K}_{\theta}\right)
$$

where $\mathbf{S}_{2}=\operatorname{diag}\left(V_{4}, V_{5}, V_{5}, V_{1}\right), \delta=(0,0,0, \hat{a})^{\prime}$ and

$$
\mathbf{K}_{\theta}=\left(\frac{\mathbf{Z}^{\prime} \mathbf{Z}}{\sigma_{G G}^{2}}+\mathbf{S}_{2}^{-1}\right)^{-1}, \quad \hat{\theta}=\mathbf{K}_{\theta}\left(\frac{\mathbf{Z}^{\prime} G D P}{\sigma_{G G}^{2}}+\mathbf{S}_{2}^{-1} \delta\right) .
$$

Finally, the conditional posterior for $\sigma_{G G}^{2}$ is 


$$
\sigma_{U U}^{2} \mid \bullet \sim I G\left(\nu+\frac{T-1}{2}, S+\frac{(G D P-\mathbf{Z} \theta)^{\prime}(G D P-\mathbf{Z} \theta)}{2}\right)
$$

\section{A.5 Sample $G D P_{E, t}$ equation}

We can rewrite the third equation of the VAR in $(9)$ as

$$
G D P_{E}=\mathbf{W} a_{32}+\epsilon_{E}, \epsilon_{E} \sim N\left(0, \sigma_{E E}^{2} \mathbf{I}_{T}\right)
$$

where

$$
\mathbf{W}=\left[\begin{array}{c}
-G D P_{1} \\
-G D P_{2} \\
\vdots \\
-G D P_{T}
\end{array}\right]
$$

and $G D P_{E}=\left(G D P_{E, 1}, \ldots, G D P_{E, T}\right)^{\prime}$. Combining (17) with the above specified priors and using the simple Bayesian linear regression formula, the conditional posterior for $a_{32}$ is

$$
a_{32} \mid \bullet \sim N\left(a_{32}, \mathbf{K}_{a_{32}}\right)
$$

where

$$
\mathbf{K}_{a_{32}}=\left(\frac{\mathbf{W}^{\prime} \mathbf{W}}{\sigma_{E E}^{2}}+V_{2}^{-1}\right)^{-1}, \quad \hat{\theta}=\mathbf{K}_{a_{32}}\left(\frac{\mathbf{W}^{\prime} G D P_{E}}{\sigma_{E E}^{2}}+V_{2}^{-1} \tilde{a}\right) .
$$

Finally, the conditional posterior for $\sigma_{E E}^{2}$ is

$$
\sigma_{E E}^{2} \mid \bullet \sim I G\left(\nu+\frac{T}{2}, S+\frac{\left(G D P_{E}-\mathbf{W} a_{32}\right)^{\prime}\left(G D P_{E}-\mathbf{W} a_{32}\right)}{2}\right)
$$

\section{A.6 Sample $G D P_{I, t}$ equation}

We can rewrite the fourth equation of the VAR in 99 as

$$
G D P_{I}=\mathbf{M} \gamma+\epsilon_{I}, \epsilon_{I} \sim N\left(0, \sigma_{I I}^{2} \mathbf{I}_{T}\right),
$$


where

$$
\mathbf{M}=\left[\begin{array}{cc}
-G D P_{1} & -G D P_{E, 1} \\
-G D P_{2} & -G D P_{E, 2} \\
\vdots & \vdots \\
-G D P_{T} & -G D P_{E, T}
\end{array}\right]
$$

$G D P_{I}=\left(G D P_{I, 1}, \ldots, G D P_{I, T}\right)^{\prime}$ and $\gamma=\left(a_{42}, a_{43}\right)^{\prime}$. Combining 20 with the above specified priors and using the simple Bayesian linear regression formula, the conditional posterior for $\gamma$ is:

$$
\gamma \mid \bullet \sim N\left(\hat{\gamma}, \mathbf{K}_{\gamma}\right)
$$

where $\mathbf{S}_{4}=\operatorname{diag}\left(V_{2}, V_{3}\right), \tilde{\delta}=(\tilde{a}, 0)^{\prime}$ and

$$
\mathbf{K}_{\gamma}=\left(\frac{\mathbf{M}^{\prime} \mathbf{M}}{\sigma_{I I}^{2}}+\mathbf{S}_{4}^{-1}\right)^{-1}, \quad \hat{\gamma}=\mathbf{K}_{\gamma}\left(\frac{\mathbf{M}^{\prime} G D P_{I}}{\sigma_{I I}^{2}}+\mathbf{S}_{4}^{-1} \tilde{\delta}\right)
$$

Finally, the conditional posterior for $\sigma_{I I}^{2}$ is

$$
\sigma_{I I}^{2} \mid \bullet \sim I G\left(\nu+\frac{T}{2}, S+\frac{\left(G D P_{I}-\mathbf{M} \gamma\right)^{\prime}\left(G D P_{I}-\mathbf{M} \gamma\right)}{2}\right)
$$

\section{A.7 Sample $G D P_{t}$}

In our model, $G D P_{t}$ is an unobserved latent variable and here we provide details on sampling this latent variable. Firstly, we rewrite $(9)$ as a combination of state and measurement equations:

$$
\tilde{\mathbf{y}}=\tilde{\mathbf{X}} G D P+\eta, \eta \sim N(0, \Omega)
$$

where $\tilde{\mathbf{y}}=\left(G D P_{E, 1}, G D P_{I, 1}+a_{43} G D P_{E, 1}, \ldots, G D P_{E, T}, G D P_{I, T}+a_{43} G D P_{E, T}\right)^{\prime}, G D P=\left(G D P_{1}, \ldots, G D P_{T}\right)^{\prime}$, $\tilde{\mathbf{X}}=\mathbf{I}_{T} \otimes\left[-a_{32}, a_{42}\right]^{\prime}$, and $\Omega=\mathbf{I}_{T} \otimes\left[\begin{array}{cc}\sigma_{E E}^{2} & 0 \\ 0 & \sigma_{E E}^{2}\end{array}\right]$. The state equations can be defined as

$$
\mathbf{H} G D P=\tilde{\alpha}+\epsilon_{G}, \epsilon_{G} \sim N\left(0, \mathbf{S}_{5}\right)
$$


where

$$
\mathbf{H}=\left[\begin{array}{cccccc}
1 & 0 & 0 & & \cdots & 0 \\
-b_{22} & 1 & 0 & & & \\
0 & -b_{22} & 1 & & & 0 \\
0 & 9 & -b_{22} & \ddots & \ddots & \vdots \\
\vdots & & \ddots & \ddots & 1 & 0 \\
0 & 0 & \cdots & 0 & -b_{22} & 1
\end{array}\right], \quad \tilde{\alpha}=\left[\begin{array}{c}
0 \\
\mu_{G D P}+b_{21} U_{1}-a_{21} U_{2} \\
\mu_{G D P}+b_{21} U_{2}-a_{21} U_{3} \\
\vdots \\
\vdots \\
\mu_{G D P}+b_{21} U_{T-1}-a_{21} U_{T}
\end{array}\right]
$$

and $\mathbf{S}_{5}=\operatorname{diag}\left(V_{G D P}, \sigma_{G G}^{2}, \ldots, \sigma_{G G}^{2}\right)$.

Next let

$$
\tilde{\mathbf{U}}=\tilde{\mathbf{H}} G D P+\epsilon_{U}, \epsilon_{U} \sim N\left(0, \sigma_{U U}^{2} \mathbf{I}_{T}\right)
$$

where

$$
\tilde{\mathbf{U}}=\left[\begin{array}{c}
U_{1}-U_{0} b_{11}-\mu_{U E} \\
U_{2}-U_{1} b_{11}-\mu_{U E} \\
\vdots \\
\vdots \\
U_{T}-U_{T-1} b_{11}-\mu_{U E}
\end{array}\right], \tilde{\mathbf{H}}=\left[\begin{array}{ccccc}
0 & \cdots & & 0 & 0 \\
b_{12} & 0 & & & \\
0 & b_{12} & 0 & 0 & \vdots \\
\vdots & & \ddots & \ddots & 0 \\
0 & \cdots & 0 & b_{12} & 0
\end{array}\right] \text {, }
$$

Therefore, combining 223, 24) and (25), the conditional posterior for $G D P$ is

$$
G D P \mid \bullet \sim N\left(G \hat{D} P, \mathbf{K}_{G D P}\right)
$$

where

$$
\mathbf{K}_{G D P}=\left(\tilde{\mathbf{X}}^{\prime} \Omega^{-1} \tilde{\mathbf{X}}+\mathbf{H}^{\prime} \mathbf{S}_{5}^{-1} \mathbf{H}+\frac{\tilde{\mathbf{H}}^{\prime} \tilde{\mathbf{H}}}{\sigma_{U U}^{2}}\right)^{-1}, \quad G \hat{D} P=\mathbf{K}_{G D P}\left(\tilde{\mathbf{X}}^{\prime} \Omega^{-1} \tilde{\mathbf{y}}+\mathbf{H}^{\prime} \mathbf{S}_{5}^{-1} \mathbf{H} \mathbf{H}^{-1} \tilde{\alpha}+\frac{\tilde{\mathbf{H}}^{\prime} \tilde{\mathbf{U}}}{\sigma_{U U}^{2}}\right) .
$$

Since the precision matrix $\mathbf{K}_{G D P}$ is a band matrix, one can sample this conditional posterior efficiently using the algorithm proposed by Chan and Jeliazkov (2009). 


\section{A.8 MCMC for Mixed Frequency Models}

When model $(9)$ is in mixed frequency, that is $U_{t}$ is a monthly variable, and $G D P_{E, t}$ and $G D P_{I, t}$ are quarterly variables, the Gibbs sampler is unchanged except for the blocks that draw $G D P_{t}, G D P_{E, t}$ and $G D P_{I, t}$.

To draw the unobserved monthly $G D P_{t}$ variable, we reparameterize the VAR in $(9)$ in a state-space representation:

$$
\mathbf{y}_{t}=\tilde{\mathbf{c}}+\tilde{\mathbf{B}} \mathbf{y}_{t-1}+\epsilon_{t}, \epsilon_{t} \sim N(0, \Sigma),
$$

where $\tilde{\mathbf{c}}=\mathbf{A}^{-1} \mathbf{c}, \tilde{\mathbf{B}}=\mathbf{A}^{-1} \mathbf{B}, \Lambda=\operatorname{diag}\left(\sigma_{U U}^{2}, \sigma_{G G}^{2}, \sigma_{E E}^{2}, \sigma_{I I}^{2}\right)$, and $\Sigma=\mathbf{A}^{-1} \Lambda \mathbf{A}^{-1^{\prime}}$. Let $m$ denote the number of monthly variables and $q$ denote the number of quarterly variables. For example, in the ADNSS MF-VAR $m=1$ and $q=3$. We can further partition (27) into:

$$
\mathbf{y}_{t}=\left[\begin{array}{c}
\tilde{\mathbf{c}}_{m} \\
\tilde{\mathbf{c}}_{q}
\end{array}\right]+\left[\begin{array}{cc}
\tilde{\mathbf{B}}_{m m} & \tilde{\mathbf{B}}_{m q} \\
\tilde{\mathbf{B}}_{q m} & \tilde{\mathbf{B}}_{q q}
\end{array}\right] \mathbf{y}_{t-1}+\epsilon_{t}, \epsilon_{t} \sim N\left(0,\left[\begin{array}{cc}
\Sigma_{m m} & \Sigma_{m q} \\
\Sigma_{q m} & \Sigma_{q q}
\end{array}\right]\right),
$$

Then our state space representation is:

$$
\mathbf{s}_{t}=\mathbf{F}_{0}+\mathbf{F}_{1} \mathbf{s}_{t-1}+\Phi_{q m}+\zeta_{t}, \zeta_{t} \sim N\left(0, \Theta_{1}\right),
$$

where $\Phi_{q m}=\left[\begin{array}{c}\tilde{\mathbf{B}}_{q m} y_{t-1}^{m} \\ \mathbf{0}_{(s-q) \times 1}\end{array}\right], y_{t-1}^{m}=\left(U_{0}, \ldots, U_{T-1}\right)^{\prime}$ is a vector that consist of all the lagged monthly variables, $\mathbf{s}_{t}=\left(G D P_{t}, G D P_{E, t}, G D P_{I, t}, \ldots, G D P_{t-4}, G D P_{E, t-4}, G D P_{I, t-4}\right)^{\prime}$ is $s \times 1$ vector, $\Theta_{1}=$ $\operatorname{blkdiag}\left(\Sigma_{q q}, \mathbf{0}_{(s-q) \times(s-q)}\right), 25$ and:

$$
\mathbf{F}_{0}=\left[\begin{array}{c}
\tilde{\mathbf{c}}_{q} \\
\mathbf{0}_{(s-q) \times 1}
\end{array}\right], \mathbf{F}_{1}=\left[\begin{array}{cccc}
\tilde{\mathbf{B}}_{q q} & 0 & \cdots & 0 \\
\mathbf{I}_{(s-q) \times 1} & 0 & & \vdots \\
0 & \ddots & \ddots & 0 \\
0 & 0 & \mathbf{I}_{(s-q) \times 1} & 0
\end{array}\right] .
$$

Then we have two measurement equations, when both the monthly and quarterly variables are observed:

$$
\hat{\mathbf{y}}_{t}=\mathbf{M}_{1} \mathbf{s}_{t}+\Phi_{m m}+v_{t}, v_{t} \sim N\left(0, \Theta_{2}\right),
$$

\footnotetext{
${ }^{25}$ blkdiag denotes a block diagonal matrix.
} 
where $\Phi_{q m}=\left[\begin{array}{c}\tilde{\mathbf{B}}_{m m} y_{t-1}^{m}+\tilde{\mathbf{c}}_{m} \\ \mathbf{0}_{(q-1) \times 1}\end{array}\right], \Theta_{2}=\operatorname{blkdiag}\left(\Sigma_{m m}, \mathbf{0}_{(q-1) \times(q-1)}\right)$,

$$
\hat{\mathbf{y}}_{t}=\left[\begin{array}{c}
U_{t} \\
G D P_{E, t} \\
G D P_{I, t}
\end{array}\right]
$$

and:

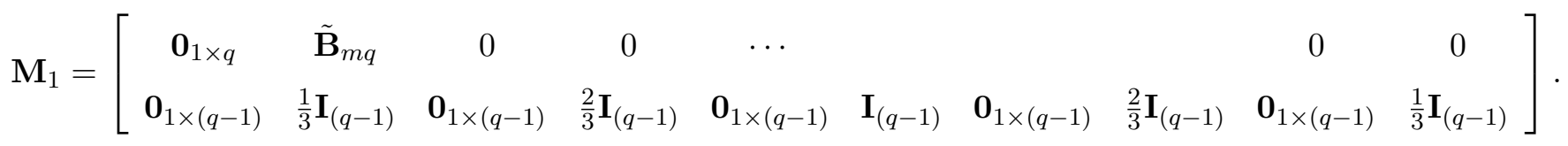

However, when only the monthly variable is observed, the measurement equation becomes:

$$
\hat{\mathbf{y}}_{t}=\mathbf{M}_{2} \mathbf{s}_{t}+\Phi_{m m}+v_{t}, v_{t} \sim N\left(0, \Theta_{2}\right),
$$

where:

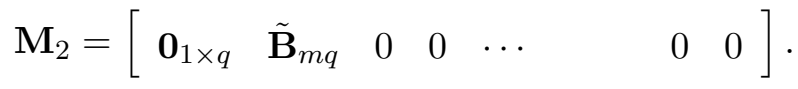

Finally, we can run the standard Kalman filtering and Carter and Kohn smoothing algorithm through (29), (30) and (31) to draw the monthly latent estimates for $G D P_{t}, G D P_{E, t}$ and $G D P_{I, t}$. 


\section{B Data Appendix}

\section{B.1 Data set for models with 8 monthly variables}

All data were gathered from the McCracken and Ng (2016) FRED-MD database. The real time data was sourced from the FRED-MD and ALFRED database.

Table 10: Data set for models with 8 monthly variables

\begin{tabular}{cccc}
\hline \hline Variables & FRED mnemonic & Frequency & Transformation \\
\hline Avg Weekly Hours : Manufacturing & AWHMAN & Monthly & Level divided by 10 \\
\hline CPI : All Items & CPIAUCSL & Monthly & $\triangle \ln x_{t} \times 100$ \\
\hline Industrial Production & INDPRO & Monthly & $\triangle \ln x_{t} \times 100$ \\
\hline Real personal consumption expenditures & DPCERA3M086SBEA & Monthly & $\triangle \ln x_{t} \times 100$ \\
\hline Effective Federal Funds Rate & FEDFUNDS & Monthly & Level \\
\hline 10-Year Treasury Rate & GS10 & Monthly & Level \\
\hline S\&P's Common Stock Price Index: Composite & S\&P 500 & Monthly & $\triangle \ln x_{t} \times 100$ \\
\hline Civilian Unemployment Rate & UNRATE & Monthly & $\triangle x_{t} \times 100$ \\
\hline Real gross domestic income & A261RX1Q020SBEA & Quarterly & $\triangle \ln x_{t} \times 400$ \\
\hline Real Gross Domestic Product & GDPC1 & Quarterly & $\triangle \ln x_{t} \times 400$ \\
\hline \hline
\end{tabular}

\section{B.2 Data set for models with 50 monthly variables}

All data were gathered from the McCracken and Ng (2016) FRED-MD database. In regards to the real time data, we sourced it from both the FRED-MD and ALFRED database. The 50 variables were designed to span 6 categories: 1) Industrial Production/Economics activity indicators - 19 variables;

2) Employments indicators - 10 variables; 3) Inflation indicators - 9 variables; 4) Financial indicators - 6 variables; 5) Stock market indicators - 2 variables; 6) Exchange rate - 2 variables. 
Table 11: Data set for models with 50 monthly variables

\begin{tabular}{|c|c|c|}
\hline Variables & FRED mnemonic & Transformation \\
\hline Industrial Production & INDPRO & $\triangle \ln x_{t} \times 100$ \\
\hline Real personal consumption expenditures & DPCERA3M086SBEA & $\triangle \ln x_{t} \times 100$ \\
\hline Real Personal Income & RPI & $\triangle \ln x_{t} \times 100$ \\
\hline Real Manu. and Trade Industries Sales & CMRMTSPLx & $\triangle \ln x_{t} \times 100$ \\
\hline Retail and Food Services Sales & RETAILx & $\triangle \ln x_{t} \times 100$ \\
\hline IP: Final Products and Nonindustrial Supplies & IPFPNSS & $\triangle \ln x_{t} \times 100$ \\
\hline IP: Final Products (Market Group) & IPFINAL & $\triangle \ln x_{t} \times 100$ \\
\hline IP: Consumer Goods & IPCONGD & $\triangle \ln x_{t} \times 100$ \\
\hline IP: Durable Consumer Goods & IPDCONGD & $\triangle \ln x_{t} \times 100$ \\
\hline IP: Nondurable Consumer Goods & IPNCONGD & $\triangle \ln x_{t} \times 100$ \\
\hline IP: Business Equipment & IPBUSEQ & $\triangle \ln x_{t} \times 100$ \\
\hline IP: Materials & IPMAT & $\triangle \ln x_{t} \times 100$ \\
\hline IP: Durable Materials & IPDMAT & $\triangle \ln x_{t} \times 100$ \\
\hline IP: Nondurable Materials & IPNMAT & $\triangle \ln x_{t} \times 100$ \\
\hline IP: Residential Utilities & IPB51222S & $\triangle \ln x_{t} \times 100$ \\
\hline IP: Fuels & IPFUELS & $\triangle \ln x_{t} \times 100$ \\
\hline Avg Weekly Hours : Manufacturing & AWHMAN & Level divided by 10 \\
\hline Capacity Utilization: Manufacturing & CUMFNS & $\triangle \ln x_{t} \times 100$ \\
\hline Civilian Labor Force & CLF16OV & $\triangle \ln x_{t} \times 100$ \\
\hline Civilian Employment & CE16OV & $\triangle \ln x_{t} \times 100$ \\
\hline Civilians Unemployed - Less Than 5 Weeks & UEMPLT 5 & $\triangle \ln x_{t} \times 100$ \\
\hline Civilians Unemployed for 5 -14 Weeks & UEMP5TO14 & $\triangle \ln x_{t} \times 100$ \\
\hline Civilians Unemployed - 15 Weeks \& Over & UEMP15OV & $\triangle \ln x_{t} \times 100$ \\
\hline Civilians Unemployed for 15-26 Weeks & UEMP15T26 & $\triangle \ln x_{t} \times 100$ \\
\hline Civilians Unemployed for 27 Weeks and Over & UEMP27OV & $\triangle \ln x_{t} \times 100$ \\
\hline
\end{tabular}


Table 12: Data set for models with 50 monthly variables (cont.)

\begin{tabular}{|c|c|c|}
\hline Variables & FRED mnemonic & Transformation \\
\hline Initial Claims & CLAIMSx & $\triangle \ln x_{t} \times 100$ \\
\hline PAYEMS & PAYEMS & $\triangle \ln x_{t} \times 100$ \\
\hline PPI: Metals and metal products: & PPICMM & $\triangle \ln x_{t} \times 100$ \\
\hline CPI : All Items & CPIAUCSL & $\triangle \ln x_{t} \times 100$ \\
\hline CPI : Apparel & CPIAPPSL & $\triangle \ln x_{t} \times 100$ \\
\hline CPI : Transportation & CPITRNSL & $\triangle \ln x_{t} \times 100$ \\
\hline CPI : Medical Care & CPIMEDSL & $\triangle \ln x_{t} \times 100$ \\
\hline CPI : Commodities & CUSR0000SAC & $\triangle \ln x_{t} \times 100$ \\
\hline CPI : Durables & CUSR0000SAD & $\triangle \ln x_{t} \times 100$ \\
\hline CPI : Services & CUSR0000SAS & $\triangle \ln x_{t} \times 100$ \\
\hline Personal Cons. Expend.: Chain Index & PCEPI & $\triangle \ln x_{t} \times 100$ \\
\hline Real M2 Money Stock & M2REAL & $\triangle \ln x_{t} \times 100$ \\
\hline Effective Federal Funds Rate & FEDFUNDS & Level \\
\hline 10-Year Treasury Rate & GS10 & Level \\
\hline Moody's Aaa Corporate Bond Minus FEDFUNDS & AAAFFM & Level \\
\hline Moody's Baa Corporate Bond Minus FEDFUNDS & BAAFFM & Level \\
\hline U.S. / U.K. Foreign Exchange Rate & EXUSUKx & $\triangle \ln x_{t} \times 100$ \\
\hline Canada / U.S. Foreign Exchange Rate & EXCAUSx & $\triangle \ln x_{t} \times 100$ \\
\hline S\&P's Common Stock Price Index: Industrials & S\&P: indust & $\triangle \ln x_{t} \times 100$ \\
\hline S\&P's Composite Common Stock: Price-Earnings Ratio & S\&P PE ratio & $\triangle \ln x_{t} \times 100$ \\
\hline S\&P's Common Stock Price Index: Composite & $\mathrm{S} \& \mathrm{P} 500$ & $\triangle \ln x_{t} \times 100$ \\
\hline Civilian Unemployment Rate & UNRATE & $\triangle x_{t} \times 100$ \\
\hline
\end{tabular}




\section{Supplementary Tables of Empirical Results}

Table 13: Properties of monthly GDP estimates, by model, when aggregated to the quarterly frequency

\begin{tabular}{|c|c|c|c|c|c|c|c|c|c|c|}
\hline \multicolumn{11}{|l|}{ SS(IV) } \\
\hline & Mean & Median & $\hat{\sigma}$ & Skew & $\hat{\rho_{1}}$ & $\hat{\rho_{2}}$ & $\hat{\rho_{3}}$ & $\hat{\rho_{4}}$ & $Q_{4}$ & $\begin{array}{l}\text { corr. } \\
\text { GDPplus }\end{array}$ \\
\hline GDP & 2.86 & 2.89 & 2.94 & -0.38 & 0.47 & 0.31 & 0.22 & 0.11 & 100.95 & 0.93 \\
\hline GDPE & 2.96 & 3.01 & 3.23 & -0.26 & 0.33 & 0.28 & 0.11 & 0.11 & 58.08 & 0.78 \\
\hline GDPI & 2.95 & 3.11 & 3.15 & -0.36 & 0.46 & 0.30 & 0.24 & 0.11 & 99.43 & 0.96 \\
\hline \multicolumn{11}{|c|}{$\mathbf{S S}(\mathbf{I V}+\mathbf{N})$} \\
\hline GDP & 2.96 & 3.06 & 3.04 & -0.37 & 0.46 & 0.31 & 0.21 & 0.11 & 98.10 & 0.92 \\
\hline GDPE & 2.96 & 3.01 & 3.23 & -0.26 & 0.33 & 0.28 & 0.11 & 0.11 & 58.10 & 0.78 \\
\hline GDPI & 2.95 & 3.11 & 3.15 & -0.36 & 0.46 & 0.30 & 0.24 & 0.11 & 99.48 & 0.96 \\
\hline \multicolumn{11}{|l|}{ SS } \\
\hline GDP & 3.03 & 3.05 & 3.12 & -0.37 & 0.47 & 0.31 & 0.22 & 0.11 & 101.12 & 0.93 \\
\hline GDPE & 2.96 & 3.01 & 3.23 & -0.26 & 0.33 & 0.28 & 0.11 & 0.11 & 58.09 & 0.78 \\
\hline GDPI & 2.95 & 3.11 & 3.15 & -0.36 & 0.46 & 0.30 & 0.24 & 0.11 & 99.48 & 0.96 \\
\hline \multicolumn{11}{|l|}{$\mathbf{S S}(\mathbf{N})$} \\
\hline GDP & 2.96 & 3.01 & 3.04 & -0.37 & 0.47 & 0.31 & 0.21 & 0.11 & 100.03 & 0.93 \\
\hline GDPE & 2.96 & 3.01 & 3.23 & -0.26 & 0.33 & 0.28 & 0.11 & 0.11 & 58.08 & 0.78 \\
\hline GDPI & 2.95 & 3.11 & 3.15 & -0.36 & 0.46 & 0.30 & 0.24 & 0.11 & 99.46 & 0.96 \\
\hline \multicolumn{11}{|c|}{ ADNSS } \\
\hline GDP & 2.75 & 2.81 & 2.83 & -0.38 & 0.47 & 0.31 & 0.22 & 0.11 & 102.61 & 0.94 \\
\hline GDPE & 2.96 & 3.01 & 3.23 & -0.26 & 0.33 & 0.28 & 0.11 & 0.11 & 58.55 & 0.78 \\
\hline GDPI & 2.95 & 3.14 & 3.15 & -0.36 & 0.46 & 0.30 & 0.24 & 0.11 & 99.92 & 0.96 \\
\hline \multicolumn{11}{|c|}{$\operatorname{ADNSS}(\mathbf{N})$} \\
\hline GDP & 2.96 & 3.06 & 3.04 & -0.37 & 0.46 & 0.31 & 0.21 & 0.11 & 98.76 & 0.92 \\
\hline GDPE & 2.96 & 3.01 & 3.23 & -0.26 & 0.33 & 0.28 & 0.11 & 0.11 & 58.53 & 0.78 \\
\hline GDPI & 2.95 & 3.14 & 3.15 & -0.36 & 0.46 & 0.30 & 0.24 & 0.11 & 99.94 & 0.96 \\
\hline \multicolumn{11}{|l|}{$\mathbf{S S}+$} \\
\hline GDP & 3.08 & 3.22 & 3.18 & -0.38 & 0.47 & 0.31 & 0.23 & 0.11 & 103.29 & 0.94 \\
\hline GDPE & 2.96 & 3.01 & 3.23 & -0.26 & 0.33 & 0.28 & 0.11 & 0.11 & 58.07 & 0.78 \\
\hline GDPI & 2.95 & 3.11 & 3.15 & -0.36 & 0.46 & 0.30 & 0.24 & 0.11 & 99.41 & 0.96 \\
\hline
\end{tabular}

Notes: The sample period is 1960q1-2019q4. $\hat{\sigma}$ is the sample standard deviation. $\widehat{\rho}_{1}-\widehat{\rho}_{4}$ are the sample autocorrelations at displacements of 1 to 4 quarters. $Q_{4}$ is the Ljung-Box serial correlation test statistic calculated using $\widehat{\rho}_{1}, \ldots, \widehat{\rho}_{4}$. corr. is the correlation coefficient against GDPplus as maintained by the Federal Reserve Bank of Philadelphia. 
Table 14: Properties of quarterly GDP estimates

\begin{tabular}{llllllllllll}
\hline \hline & Mean & Median & $\hat{\sigma}$ & Skewness & $\hat{\rho_{1}}$ & $\hat{\rho_{2}}$ & $\hat{\rho_{3}}$ & $\hat{\rho_{4}}$ & $Q_{4}$ & $\begin{array}{l}\text { corr. } \\
\text { GDPplus }\end{array}$ \\
\hline GDPE & 2.96 & 2.98 & 3.24 & -0.26 & 0.32 & 0.28 & 0.11 & 0.11 & 57.02 & 0.78 \\
$G D P_{I}$ & 2.95 & 3.15 & 3.15 & -0.36 & 0.45 & 0.29 & 0.23 & 0.11 & 98.07 & 0.96 \\
GDPplus & 2.98 & 3.13 & 2.47 & -0.46 & 0.74 & 0.50 & 0.34 & 0.18 & 239.57 & 1.00 \\
ADNSS_B1 & 3.05 & 3.16 & 2.60 & -0.44 & 0.64 & 0.42 & 0.27 & 0.14 & 169.41 & 0.97 \\
ADNSS_B2 & 2.96 & 3.04 & 2.72 & -0.45 & 0.53 & 0.34 & 0.22 & 0.10 & 119.93 & 0.94 \\
\hline \hline
\end{tabular}

Notes: The sample period is 1960q1-2019q4. $\hat{\sigma}$ is the sample standard deviation. $\widehat{\rho}_{1}-\widehat{\rho}_{4}$ are the sample autocorrelations at displacements of 1 to 4 quarters. $Q_{4}$ is the Ljung-Box serial correlation test statistic calculated using $\widehat{\rho}_{1}, \ldots, \widehat{\rho}_{4}$. corr. is the correlation coefficient against GDPplus as maintained by the Federal Reserve Bank of Philadelphia. ADNSS_B1 and ADNSS_B2 are the posterior median estimates of true GDP from the two Bayesian quarterly econometric models considered in sections 4.1 and 4.2 , respectively.

Table 15: Correlation of the posterior median of monthly $G D P_{E}$ growth with selected business cycle indicators and alternative estimates of monthly GDP growth (1960m1-2019m12)

\begin{tabular}{lccccc}
\hline \hline & OECD & S\&P500 & IPI & Unemployment & PMI \\
\hline $\mathbf{S S}(\mathbf{I V})$ & 0.84 & 0.26 & 0.76 & -0.63 & 0.64 \\
\hline $\mathbf{S S}(\mathbf{I V}+\mathbf{N})$ & 0.84 & 0.26 & 0.76 & -0.63 & 0.64 \\
\hline $\mathbf{S S}$ & 0.84 & 0.26 & 0.76 & -0.63 & 0.64 \\
\hline $\mathbf{S S}(\mathbf{N})$ & 0.84 & 0.26 & 0.76 & -0.63 & 0.64 \\
\hline $\mathbf{A D N S S}$ & 0.84 & 0.26 & 0.77 & -0.64 & 0.65 \\
\hline $\mathbf{A N D S S}(\mathbf{N})$ & 0.84 & 0.26 & 0.77 & -0.64 & 0.65 \\
\hline $\mathbf{S S}+$ & 0.84 & 0.25 & 0.77 & -0.63 & 0.64 \\
\hline \hline
\end{tabular}

\begin{tabular}{lccccc}
\hline \hline & Employment & Stock Watson & IHS Markit & ADS Index & BBK \\
\hline SS(IV) & 0.67 & 0.93 & 0.45 & 0.71 & 1.00 \\
\hline SS(IV+N) & 0.67 & 0.93 & 0.45 & 0.71 & 1.00 \\
\hline SS & 0.67 & 0.93 & 0.45 & 0.71 & 1.00 \\
\hline SS(N) & 0.67 & 0.93 & 0.45 & 0.71 & 1.00 \\
\hline $\mathbf{A D N S S}$ & 0.67 & 0.93 & 0.46 & 0.72 & 1.00 \\
\hline $\mathbf{A N D S S}(\mathbf{N})$ & 0.67 & 0.93 & 0.46 & 0.72 & 1.00 \\
\hline $\mathbf{S S}+$ & 0.67 & 0.93 & 0.47 & 0.72 & 0.99 \\
\hline \hline
\end{tabular}

Notes: All monthly indicators except PMI are analyzed in quarterly (quarter-over-quarter) annualized percent changes. PMI is analyzed in levels. Due to data availability, the correlations reported for Stock-Watson and IHS Markit are over the shorter sample periods of $1960 \mathrm{~m} 1-2010 \mathrm{~m} 6$ and $1992 \mathrm{~m} 4-2019 \mathrm{~m} 12$, respectively. 
Table 16: Correlation of the posterior median of monthly $G D P_{I}$ growth with selected business cycle indicators and alternative estimates of monthly GDP growth (1960m1-2019m12)

\begin{tabular}{lccccc}
\hline \hline & OECD & S\&P500 & IPI & Unemployment & PMI \\
\hline $\mathbf{S S}(\mathbf{I V})$ & 0.77 & 0.26 & 0.79 & -0.66 & 0.67 \\
\hline $\mathbf{S S}(\mathbf{I V}+\mathbf{N})$ & 0.77 & 0.26 & 0.79 & -0.66 & 0.67 \\
\hline $\mathbf{S S}$ & 0.77 & 0.26 & 0.79 & -0.66 & 0.67 \\
\hline $\mathbf{S S}(\mathbf{N})$ & 0.77 & 0.26 & 0.79 & -0.66 & 0.67 \\
\hline $\mathbf{A D N S S}$ & 0.77 & 0.27 & 0.79 & -0.67 & 0.67 \\
\hline $\mathbf{A N D S S}(\mathbf{N})$ & 0.77 & 0.27 & 0.79 & -0.67 & 0.67 \\
\hline $\mathbf{S S}+$ & 0.77 & 0.26 & 0.79 & -0.66 & 0.67 \\
\hline \hline
\end{tabular}

\begin{tabular}{lccccc}
\hline \hline & Employment & Stock Watson & IHS Markit & ADS Index & BBK \\
\hline $\mathbf{S S}(\mathbf{I V})$ & 0.68 & 0.92 & 0.50 & 0.76 & 0.84 \\
\hline $\mathbf{S S}(\mathbf{I V}+\mathbf{N})$ & 0.68 & 0.92 & 0.50 & 0.76 & 0.84 \\
\hline $\mathbf{S S}$ & 0.68 & 0.92 & 0.50 & 0.76 & 0.84 \\
\hline $\mathbf{S S}(\mathbf{N})$ & 0.68 & 0.92 & 0.50 & 0.76 & 0.84 \\
\hline $\mathbf{A D N S S}$ & 0.68 & 0.92 & 0.51 & 0.76 & 0.84 \\
\hline $\mathbf{A N D S S}(\mathbf{N})$ & 0.68 & 0.92 & 0.51 & 0.76 & 0.84 \\
\hline $\mathbf{S S}+$ & 0.68 & 0.92 & 0.52 & 0.76 & 0.84 \\
\hline \hline
\end{tabular}

Notes: All monthly indicators except PMI are analyzed in quarterly (quarter-over-quarter) annualized percent changes. PMI is analyzed in levels. Due to data availability, the correlations reported for Stock-Watson and IHS Markit are over the shorter sample periods of 1960m1-2010m6 and 1992m4-2019m12, respectively. 
Table 17: Business cycles features: Classification ability of the monthly GDP posterior mean estimates from the $7 \mathrm{MF}$-VAR models. Area under the receiver operating characteristic curve (AUC) values and threshold estimates that optimize classification ability when hits and misses are given equal weight

\begin{tabular}{cccccccc}
\hline \hline Variables & SS(IV) & SS $(\mathrm{IV}+\mathrm{N})$ & $\mathrm{SS}$ & $\mathrm{SS}(\mathrm{N})$ & ADNSS & ADNSS(N) & SS + \\
\hline AUC estimates \\
\hline True $G D P$ & 0.92 & 0.92 & 0.92 & 0.92 & 0.92 & 0.92 & 0.92 \\
\hline$G D P_{E}$ & 0.90 & 0.91 & 0.90 & 0.90 & 0.90 & 0.90 & 0.90 \\
\hline$G D P_{I}$ & 0.91 & 0.91 & 0.91 & 0.91 & 0.91 & 0.91 & 0.91 \\
\hline \multicolumn{7}{c}{ Optimal threshold parameter } \\
\hline True $G D P$ & -0.90 & -0.89 & -0.95 & -0.91 & -0.91 & -0.94 & -1.01 \\
\hline$G D P_{E}$ & -1.00 & -0.97 & -1.00 & -0.99 & -1.11 & -1.07 & -0.99 \\
\hline$G D P_{I}$ & -1.04 & -1.07 & -1.03 & -1.05 & -1.11 & -1.15 & -1.04 \\
\hline \hline
\end{tabular}

Notes: Sample: 1960m1-2019m12 


\section{References in the Appendix}

Chan, J. C., \& Jeliazkov, I. (2009). Efficient simulation and integrated likelihood estimation in state space models. International Journal of Mathematical Modelling and Numerical Optimisation, 1(1-2), 101-120.

Carriero, A., Clark, T. E., \& Marcellino, M. (2019). Large Bayesian vector autoregressions with stochastic volatility and non-conjugate priors. Journal of Econometrics, 212(1), 137-154.

Koop, G., McIntyre, S., Mitchell, J., \& Poon, A. (2020). Regional output growth in the United Kingdom: More timely and higher frequency estimates from 1970. Journal of Applied Econometrics, 35(2), 176-197.

McCracken, M. and Ng, S. (2016). FRED-MD: A monthly database for macroeconomic research. Journal of Business and Economic Statistics, 34, 574-589.

Schorfheide, F. and Song, D. (2015). Real-time forecasting with a mixed-frequency VAR. Journal of Business and Economic Statistics, 33(3), 366-380. 